\title{
Aggregation-Induced Emission-Based Polymer Materials: Ratiometric Fluorescence Responses Controlled by Hydrostatic Pressure
}

\author{
Kotoe Nakasha ${ }^{\dagger}$ and Gaku Fukuhara*,†,
}

${ }^{\dagger}$ Department of Chemistry, Tokyo Institute of Technology, 2-12-1 Ookayama, Meguro-ku, Tokyo 152-8551, Japan

\JST, PRESTO, 4-1-8 Honcho, Kawaguchi, Saitama, 332-0012, Japan

*E-mail: gaku@chem.titech.ac.jp 


\section{Synthesis and Characterization}

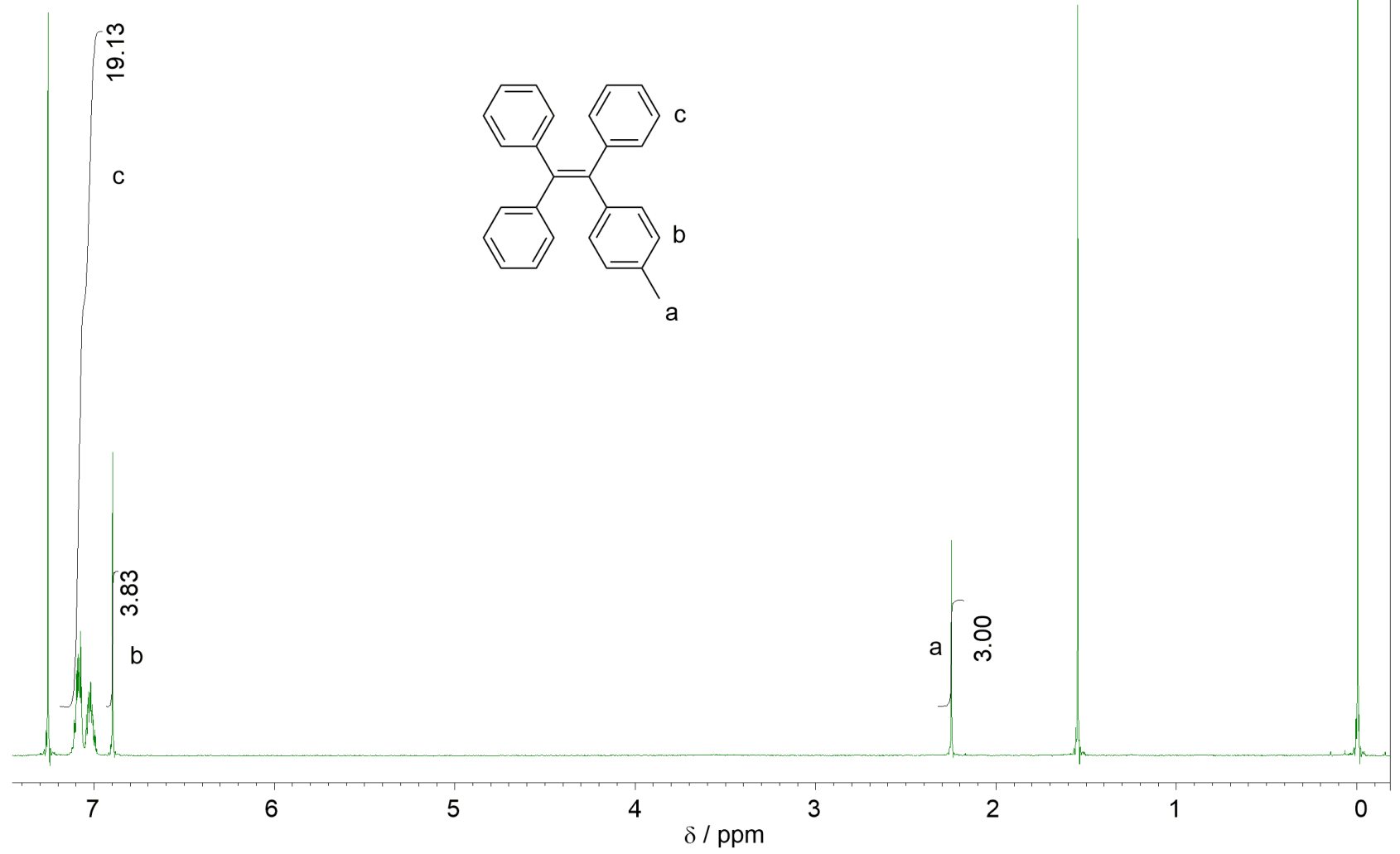

Figure S1. ${ }^{1} \mathrm{H}$ NMR spectrum (400 MHz) of 1-(4-methylphenyl)-1,2,2,-triphenylethene (TPE-ref) in $\mathrm{CDCl}_{3}$.

Reported ${ }^{1}{ }^{1} \mathrm{H}$ NMR (400 MHz, $\left.\mathrm{CDCl}_{3}\right) \delta_{\mathrm{H}} 7.12-6.99(\mathrm{~m}, 15 \mathrm{H}), 6.90$ (s, 4H), 2.24 (s, 3H).

Observed; ${ }^{1} \mathrm{H}$ NMR (400 MHz, $\left.\mathrm{CDCl}_{3}\right) \delta_{\mathrm{H}}$ 7.02-7.10 (m, 19H), 6.90 (s, 4H), 2.24 (s, 3H). 


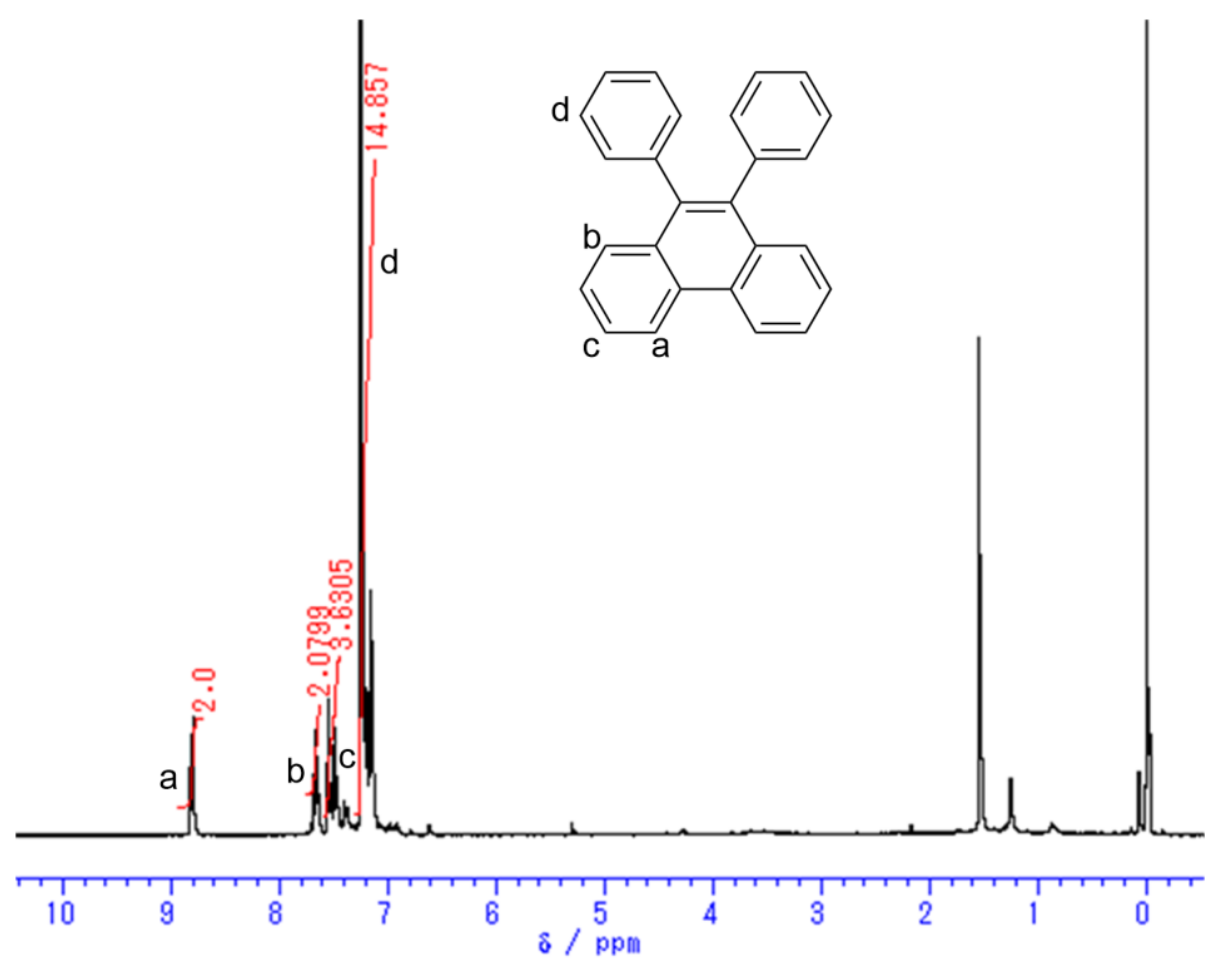

Figure S2. ${ }^{1} \mathrm{H}$ NMR spectrum (400 MHz) of 9,10-diphenylphenanthrene (DPP) in $\mathrm{CDCl}_{3}$.

Reported; ${ }^{2}{ }^{1} \mathrm{H}$ NMR (400 MHz, $\left.\mathrm{CDCl}_{3}\right) \delta_{\mathrm{H}} 8.81(\mathrm{~d}, 2 \mathrm{H}), 7.69-7.64(\mathrm{~m}, 2 \mathrm{H}), 7.58-7.54(\mathrm{~m}, 2 \mathrm{H})$, 7.51-7.46 (m, 2H), 7.27-7.14 (m, 10H).

Observed; ${ }^{1} \mathrm{H}$ NMR $\left(400 \mathrm{MHz}, \mathrm{CDCl}_{3}\right) \delta_{\mathrm{H}} 8.81(\mathrm{~d}, 2 \mathrm{H}), 7.69-7.64(\mathrm{~m}, 2 \mathrm{H}), 7.56-7.46(\mathrm{~m}, 2 \mathrm{H}, 2 \mathrm{H})$, $7.25-7.14(\mathrm{~m}, 15 \mathrm{H})$.

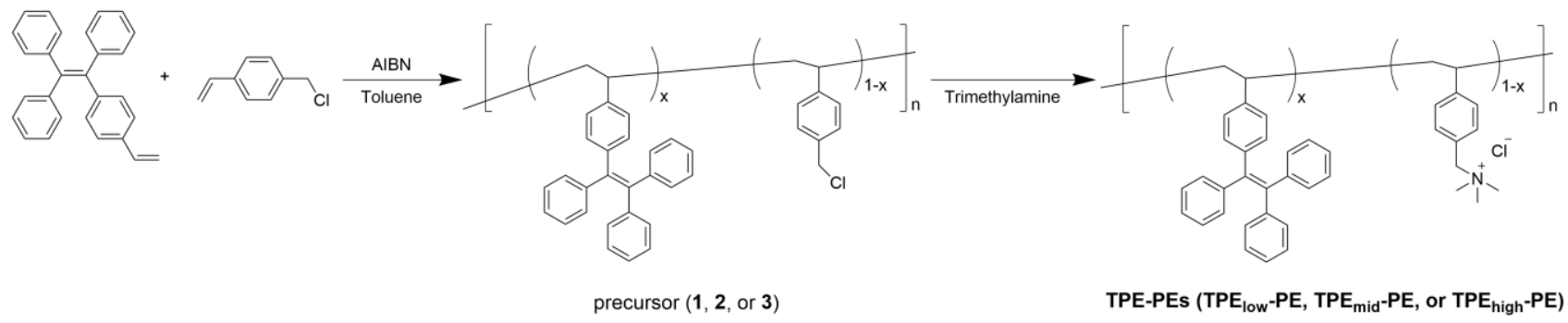

Figure S3. Synthetic scheme of TPE-PEs. 


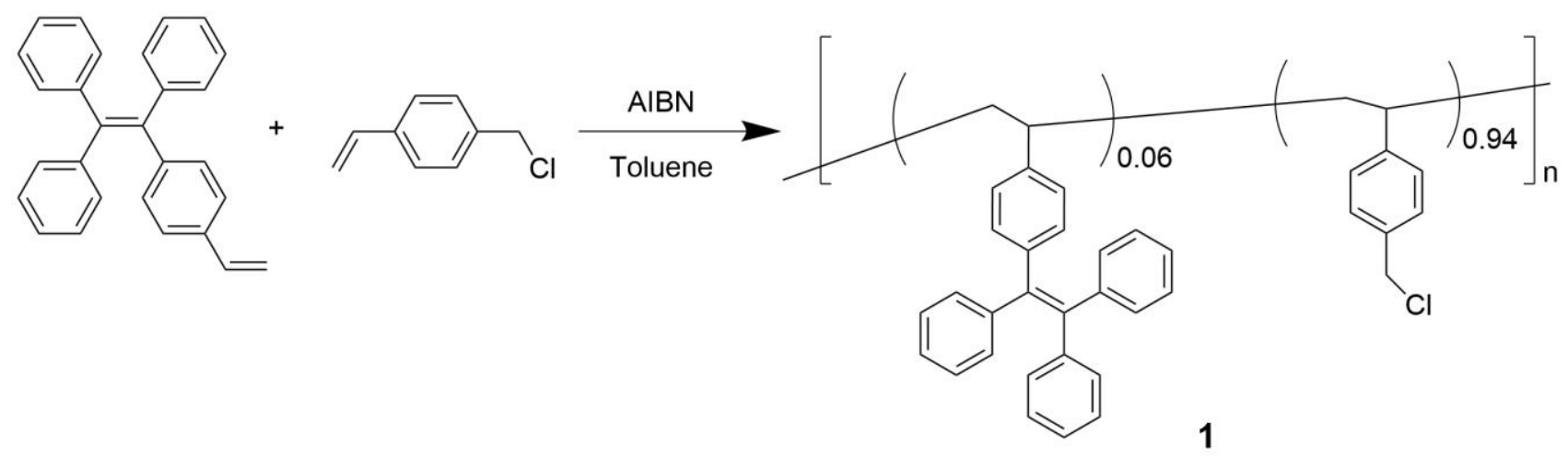

In a $5 \mathrm{~mL}$ pear flask, (2-(4-vinylphenyl)ethene-1,1,2-triyl)tribenzene ${ }^{3}$ (52.6 mg, $0.147 \mathrm{mmol}$ ), AIBN (4.84 mg, $\left.2.95 \times 10^{-2} \mathrm{mmol}\right)$, and 4-(chloromethyl)styrene $(0.19 \mathrm{~mL}, 1.35 \mathrm{mmol})$ were dissolved in toluene $(0.10 \mathrm{~mL})$. The reaction solution was deaerated by three freeze-pump-thaw cycles saturated with $\mathrm{N}_{2}$ gas, and then heated to $85^{\circ} \mathrm{C}$ for $24 \mathrm{~h}$. After cooling to room temperature, the concentrated reaction mixture was poured onto methanol $(10 \mathrm{~mL})$. The precipitate thus obtained was collected, triturated, and washed with methanol, and then dried under high vacuum to afford the precursor (1) (288.1 mg, $1.61 \mathrm{mmol}$ in monomer unit) as a white solid. ${ }^{1} \mathrm{H} \mathrm{NMR}\left(400 \mathrm{MHz}, \mathrm{CDCl}_{3}\right)$ : $\delta_{\mathrm{H}}$ 7.21-6.74 (br, 19H), 6.70-6.11 (br, 10H), 4.69-4.23 (br, 13H), 1.88-1.09 (br, 21H); ${ }^{13} \mathrm{C} \mathrm{NMR} \mathrm{(100} \mathrm{MHz,}$ $\left.\mathrm{CDCl}_{3}\right): \delta_{\mathrm{C}} 134.9,131.3,129.0,128.4,128.2,127.8,127.6,125.3,46.3,40.2$; IR $v 3730,3626,3023$, 2912, 2170, 2078, 2020, 1976, 1610, 1509, 1442, 1420, 1263, 1182, 1108, 1018, 911, 821, 743, 699, $671,637,606 \mathrm{~cm}^{-1} ; M_{\mathrm{n}}=2.1 \times 10^{4}$ and PDI $=2.6($ determined by GPC). 


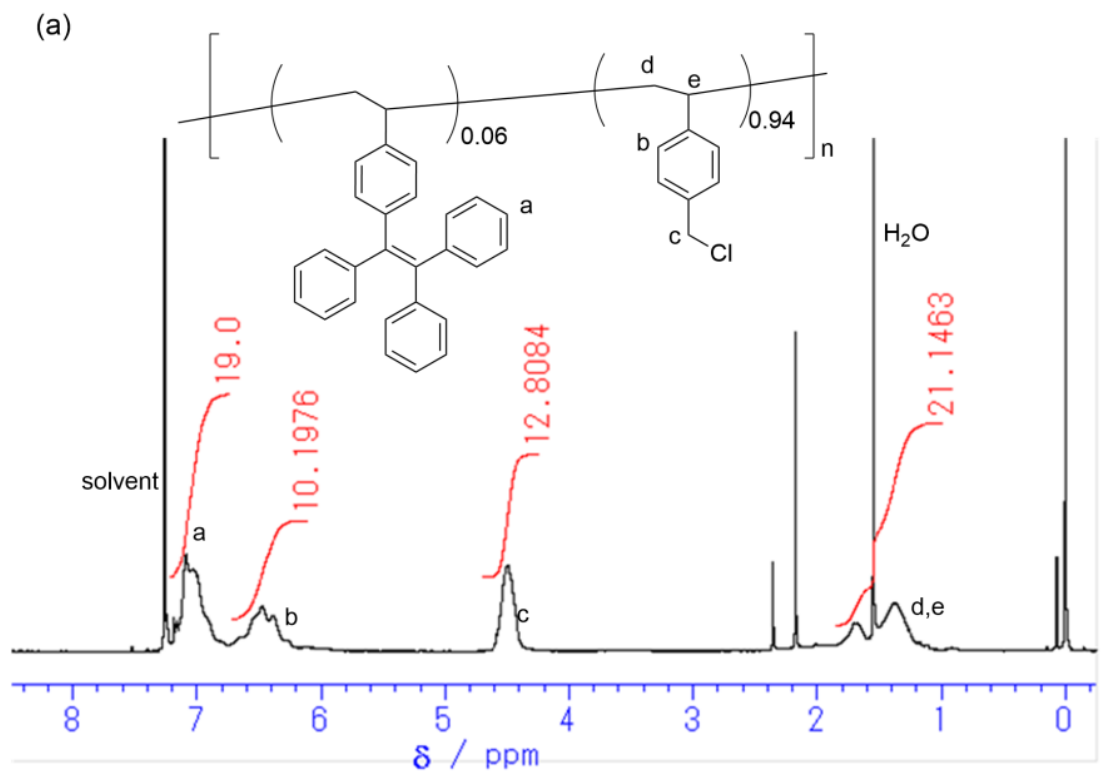

(b)

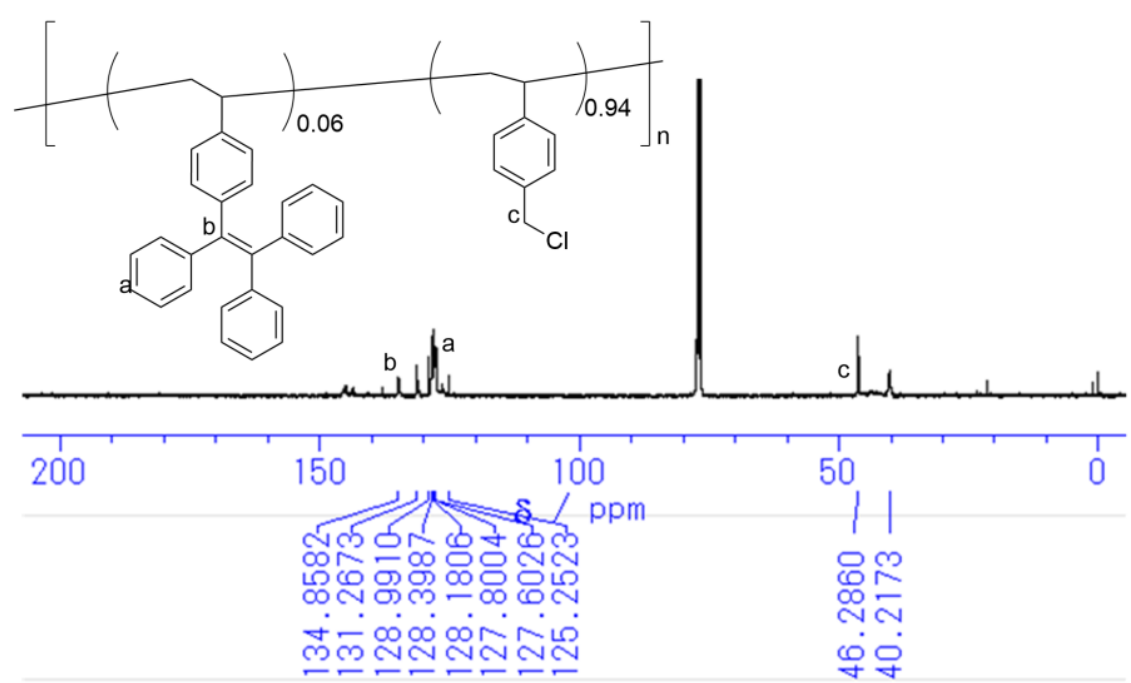

Figure S4. (a) ${ }^{1} \mathrm{H}(400 \mathrm{MHz})$ and (b) ${ }^{13} \mathrm{C}$ NMR (100 MHz) spectra of the precursor (1) of TPE ${ }_{\text {low }}$-PE in $\mathrm{CDCl}_{3}$. 


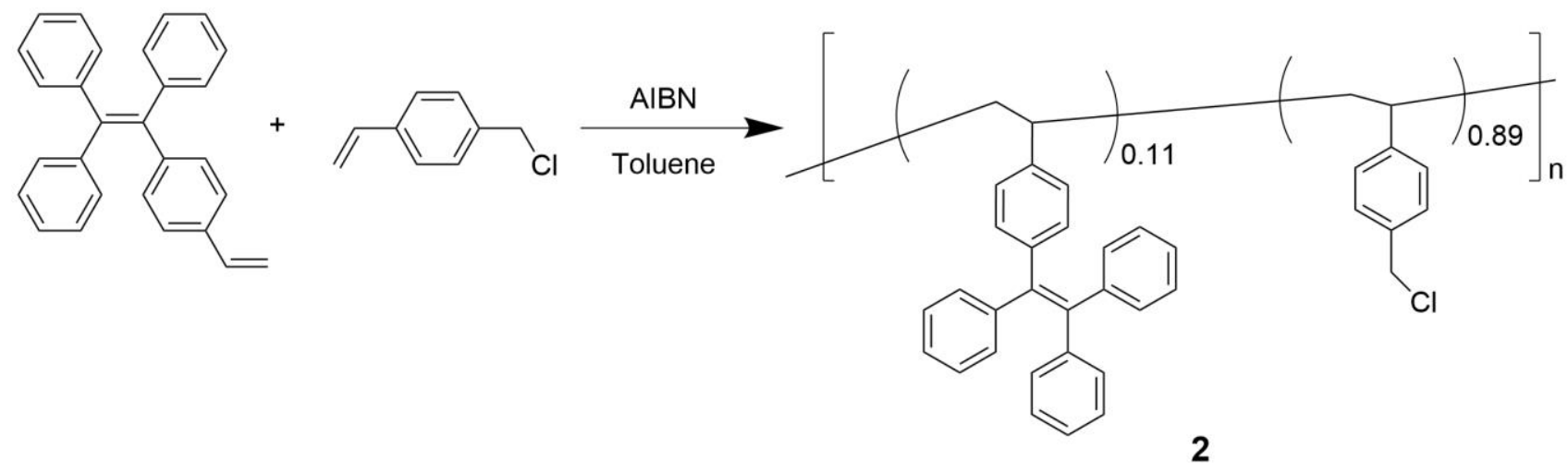

In a $10 \mathrm{~mL}$ pear flask, (2-(4-vinylphenyl)ethene-1,1,2-triyl)tribenzene ${ }^{3}$ (55.8 $\mathrm{mg}, 0.156 \mathrm{mmol}$ ), AIBN (5.01 mg, $\left.3.05 \times 10^{-2} \mathrm{mmol}\right)$, and 4-(chloromethyl)styrene $(0.19 \mathrm{~mL}, 1.35 \mathrm{mmol})$ were dissolved in toluene $(2.0 \mathrm{~mL})$. The reaction solution was deaerated by three freeze-pump-thaw cycles saturated with $\mathrm{N}_{2}$ gas, and then heated to $82{ }^{\circ} \mathrm{C}$ for $23 \mathrm{~h}$. After cooling to room temperature, the concentrated reaction mixture was poured onto methanol $(40 \mathrm{~mL})$. The precipitate thus obtained was collected, triturated, and washed with methanol, and then dried under high vacuum to afford the precursor (2) (48.7 mg, $0.165 \mathrm{mmol}$ in monomer unit) as a white solid. ${ }^{1} \mathrm{H} \mathrm{NMR}\left(400 \mathrm{MHz}, \mathrm{CDCl}_{3}\right)$ : $\delta_{\mathrm{H}}$ 7.22-6.85 (br, 19H), 6.72-6.27 (br, 8H), 4.66-4.38 (br, 12H), 1.84-1.22 (br, 23H); ${ }^{13} \mathrm{C}$ NMR (100 $\left.\mathrm{MHz}, \mathrm{CDCl}_{3}\right): \delta_{\mathrm{C}} 130.2,127.4,126.6,45.2$; IR v 3853, 3734, 3567, 3014, 1943, 1716, 1558, 1541, $1216,1139,1018,822,719,670,617 \mathrm{~cm}^{-1} ; M_{\mathrm{n}}=6.1 \times 10^{3}$ and PDI $=1.4$ (determined by GPC). 
(a)

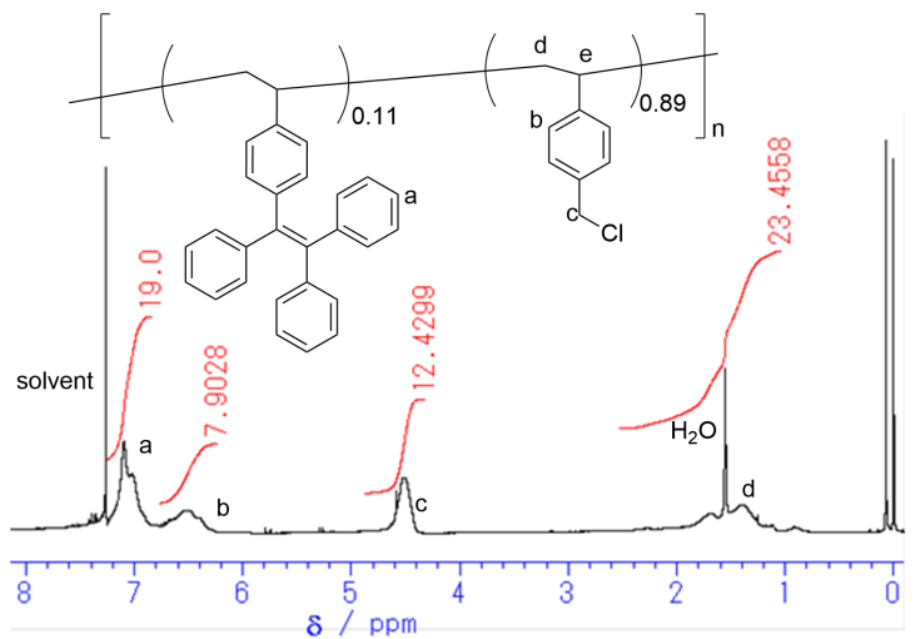

(b)

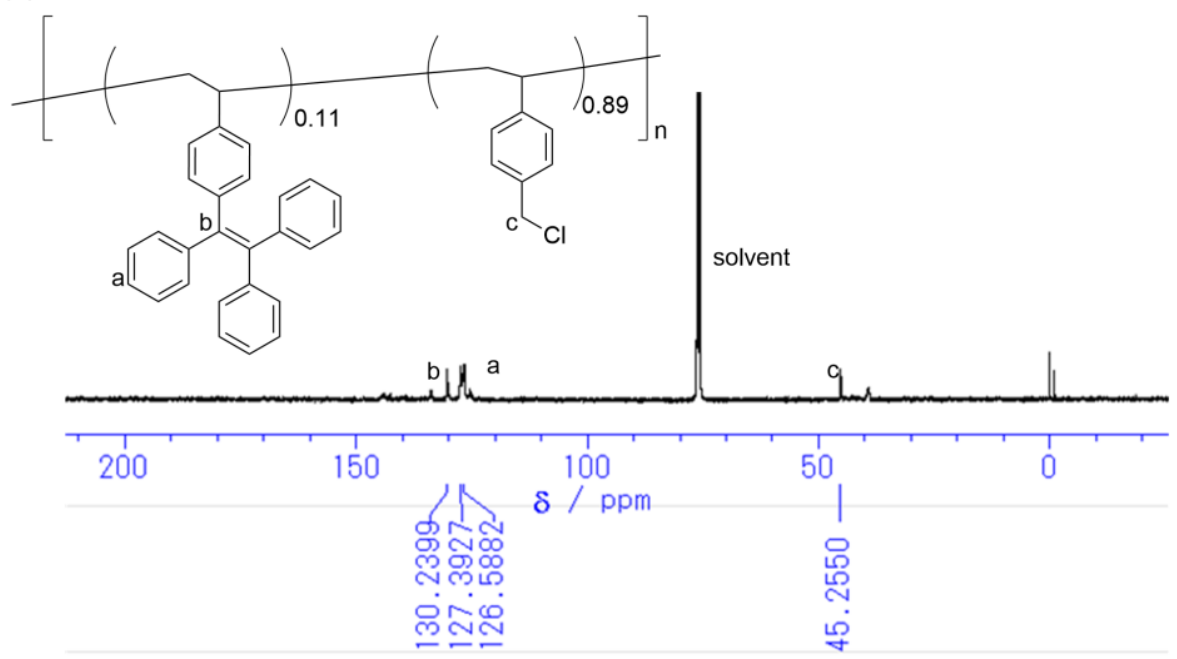

Figure S5. (a) ${ }^{1} \mathrm{H}(400 \mathrm{MHz})$ and (b) ${ }^{13} \mathrm{C}$ NMR (100 MHz) spectra of the precursor (2) of TPE mid-PE in $\mathrm{CDCl}_{3}$. 


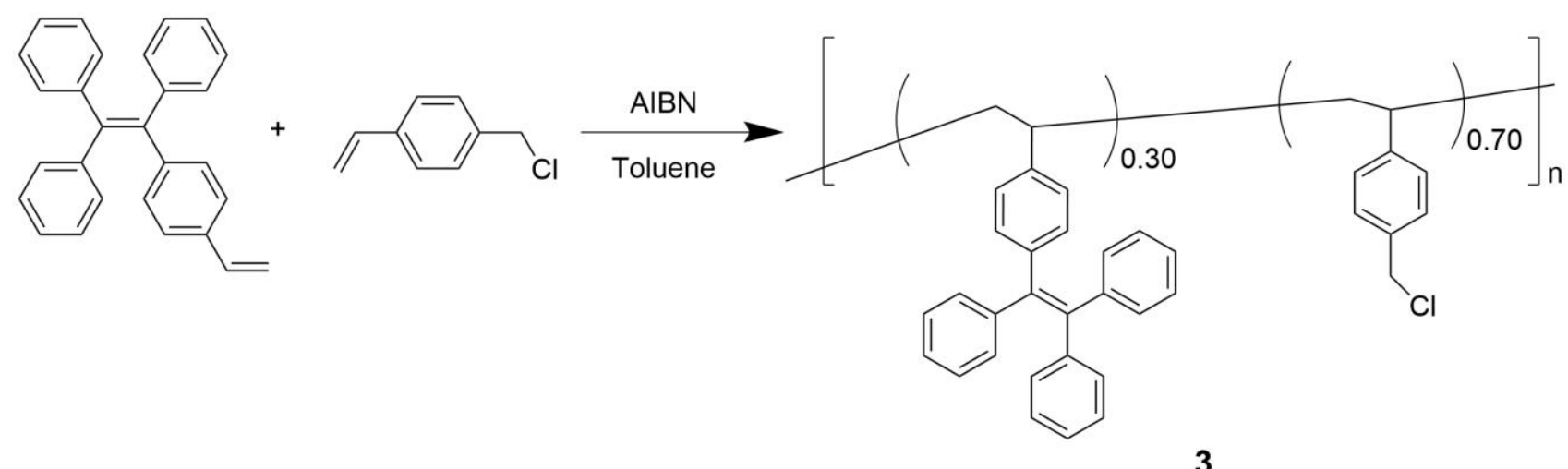

3

In a $10 \mathrm{~mL}$ pear flask, (2-(4-vinylphenyl)ethene-1,1,2-triyl)tribenzene ${ }^{3}(55.2 \mathrm{mg}, 0.154 \mathrm{mmol})$, AIBN (4.88 mg, $\left.2.97 \times 10^{-2} \mathrm{mmol}\right)$, and 4-(chloromethyl)styrene $(0.021 \mathrm{~mL}, 0.149 \mathrm{mmol})$ were dissolved in toluene $(2.0 \mathrm{~mL})$. The reaction solution was deaerated by three freeze-pump-thaw cycles saturated with $\mathrm{N}_{2}$ gas, and then heated to $82{ }^{\circ} \mathrm{C}$ for $23 \mathrm{~h}$. After cooling to room temperature, the concentrated reaction mixture was poured onto methanol $(40 \mathrm{~mL})$. The precipitate thus obtained was collected, triturated, and washed with methanol, and then dried under high vacuum to afford the precursor (3) $\left(29.2 \mathrm{mg}, 0.128 \mathrm{mmol}\right.$ in monomer unit) as a white solid. ${ }^{1} \mathrm{H} \mathrm{NMR}\left(400 \mathrm{MHz}, \mathrm{CDCl}_{3}\right)$ : $\delta_{\mathrm{H}}$ 7.17-6.72 (br, 19H), 6.70-5.80 (br, 1H), 4.59-4.01 (br, 3H), 1.99-0.95 (br, $\left.11 \mathrm{H}\right) ;{ }^{13} \mathrm{C}$ NMR $(100$ $\left.\mathrm{MHz}, \mathrm{CDCl}_{3}\right): \delta_{\mathrm{C}} 130.3,126.6,45.0$; IR $v 3853,3734,3015,2970,2170,1869,1734,1541,1521$, $1507,1363,1092,1017,797,719,670 \mathrm{~cm}^{-1} ; M_{\mathrm{n}}=7.2 \times 10^{3}$ and PDI $=2.1$ (determined by GPC). 


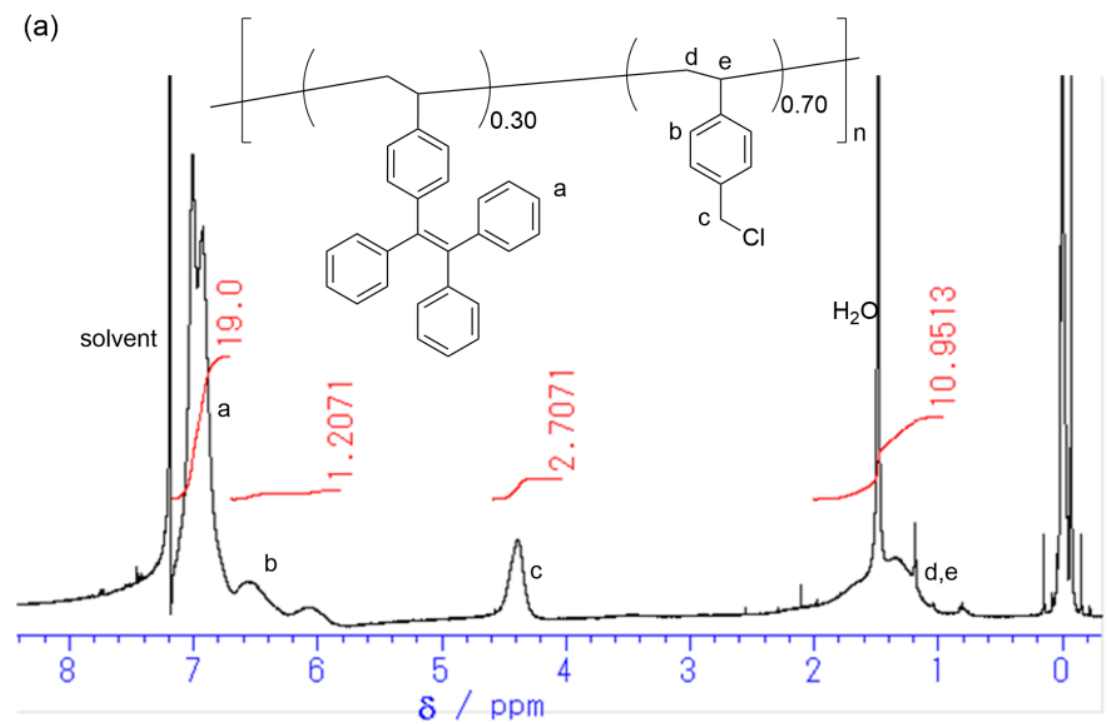

(b)

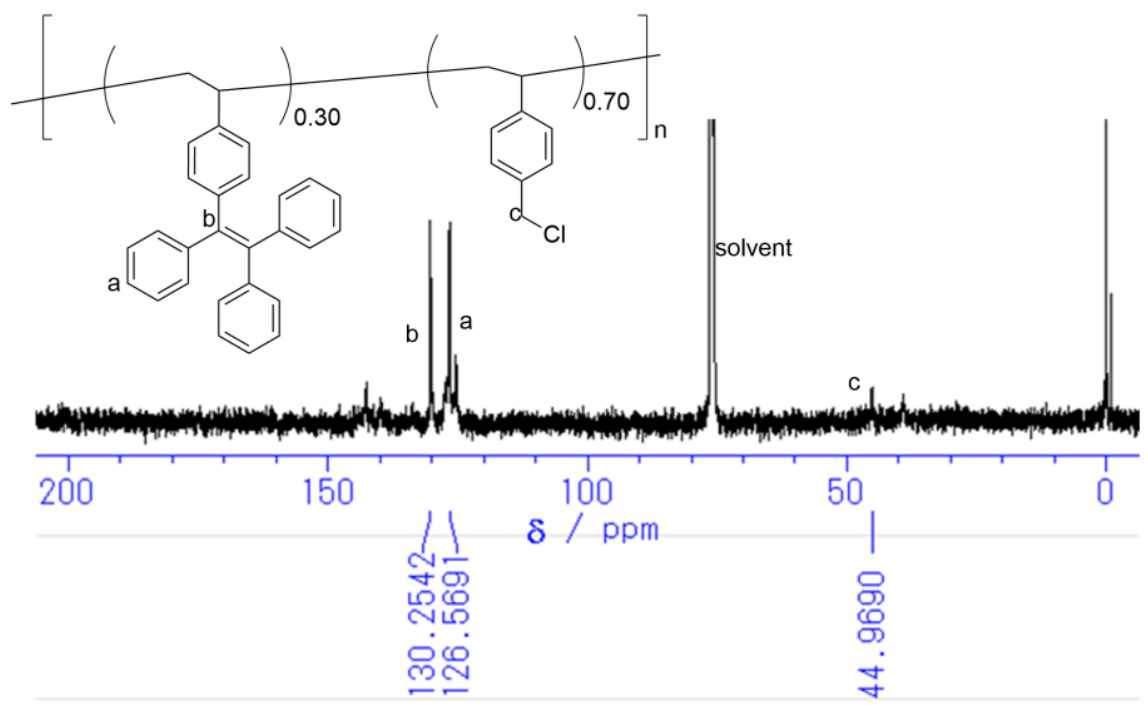

Figure S6. (a) ${ }^{1} \mathrm{H}(400 \mathrm{MHz})$ and (b) ${ }^{13} \mathrm{C}$ NMR (100 MHz) spectra of the precursor (3) of TPE ${ }_{\text {high-PE }}$ in $\mathrm{CDCl}_{3}$. 


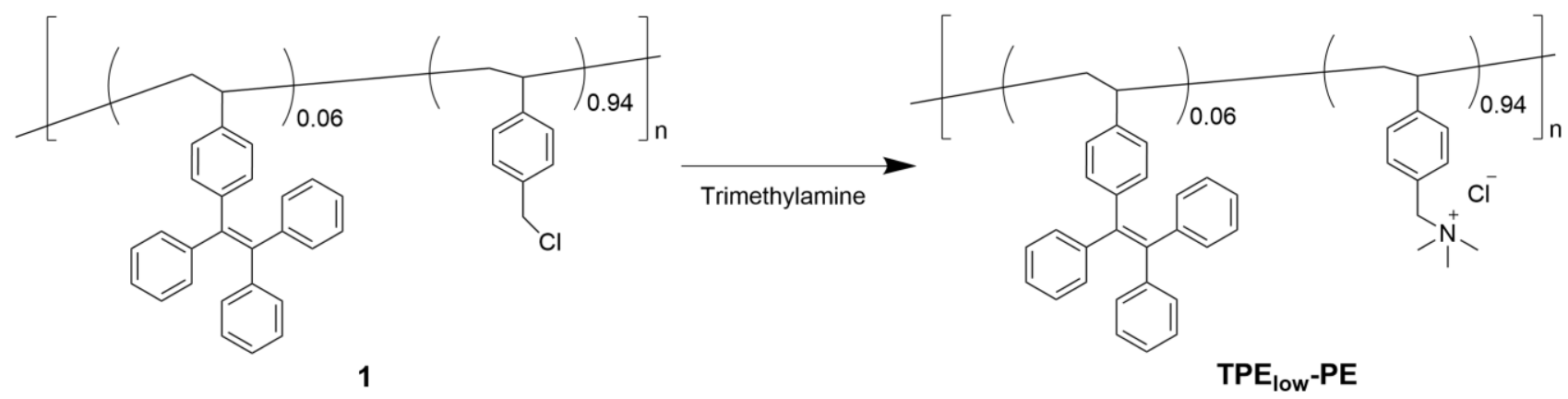

In a $20 \mathrm{~mL}$ round-bottomed flask, the precursor (1) was dissolved in trimethylamine (25\% in methanol) $(6.0 \mathrm{~mL})$. The reaction mixture was stirred at room temperature for $15 \mathrm{~h}$. The solvent was evaporated, washed with methanol (five times), and then dried in vacuo to afford TPE $\mathrm{mg}, 1.27 \mathrm{mmol}$ in monomer unit) as a white solid. ${ }^{1} \mathrm{H}$ NMR (400 MHz, DMSO- $\left.d_{6}\right): \delta_{\mathrm{H}} 7.77-6.87$ (br, 19H), 6.78-6.24 (br, 3H), 5.22-4.53 (br, 7H), 3.38-2.91 (br, 82H), 2.01-0.93 (br, 14H); ${ }^{13} \mathrm{C}$ NMR (100 MHz, DMSO- $\left.d_{6}\right)$ : $\delta_{\mathrm{C}} 133.0,130.8,128.4,66.4,51.8,49.1$; IR $v 3730,3367,3018,2963,2921$, 2189, 2165, 2052, 2009, 1999, 1979, 1613, 1512, 1477, 1415, 1384, 1260, 1221, 1092, 1020, 992, 986, 924, 889, 857, 822, $703 \mathrm{~cm}^{-1}$. The degree of substitution (DS; $x$ ) of TPElow-PE was determined by UV/vis spectroscopy using a DMSO solution of 1-(4-methylphenyl)-1,2,2,-triphenylethene (TPE-ref) ${ }^{1}$ as an authentic compound. Thus, the DS (x) of TPE the equation as follows: Abs $\left(\mathbf{T P E}_{\text {low }} \mathbf{P E}\right)=\varepsilon(1$-(4-methylphenyl)-1,2,2,-triphenylethene $) \times c$ (concentration of TPE $\mathbf{l o w}_{-} \mathbf{P E}$ in a chromophore unit) $\times l$ (path length). 
(a)

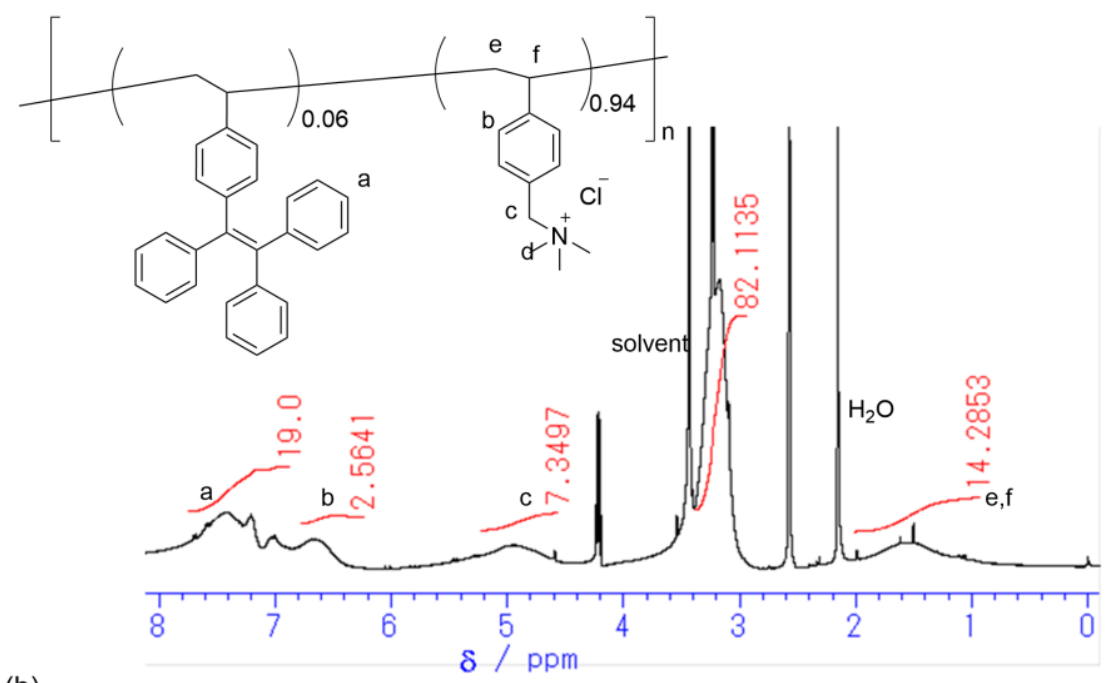

(b)

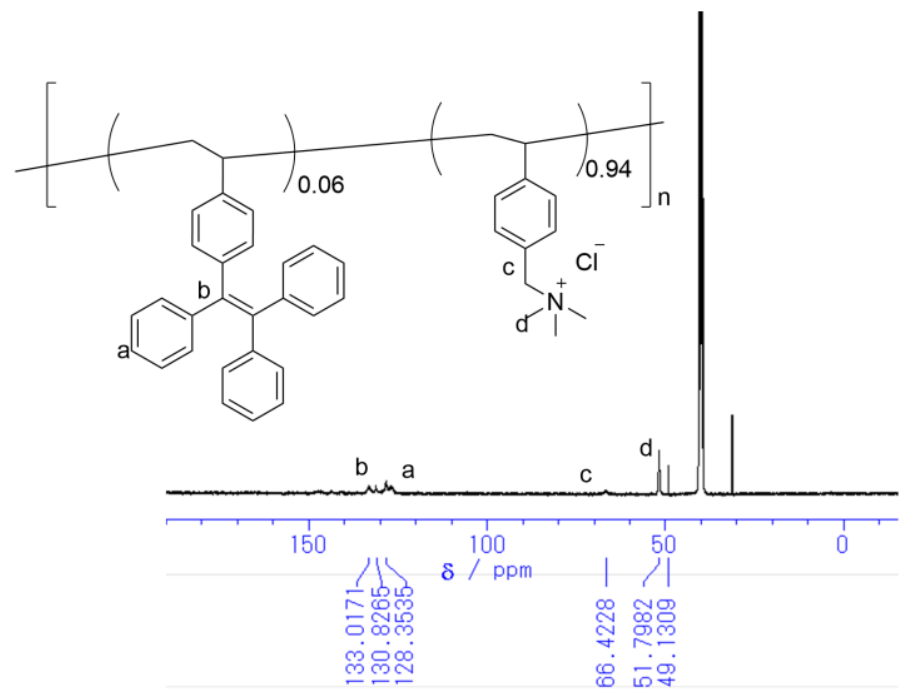

Figure S7. (a) ${ }^{1} \mathrm{H}(400 \mathrm{MHz})$ and (b) ${ }^{13} \mathrm{C}$ NMR (100 MHz) spectra of TPE 


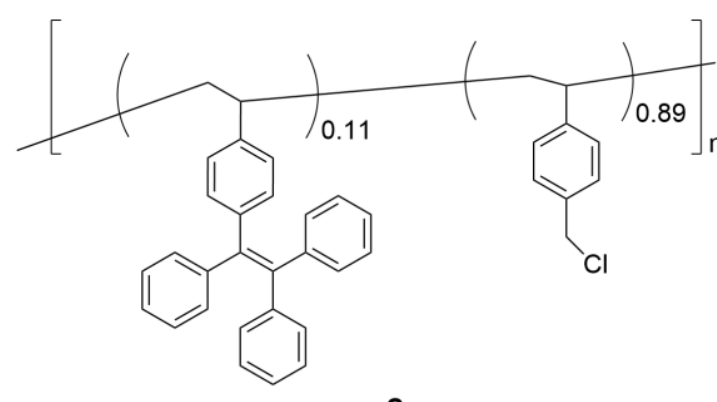

2

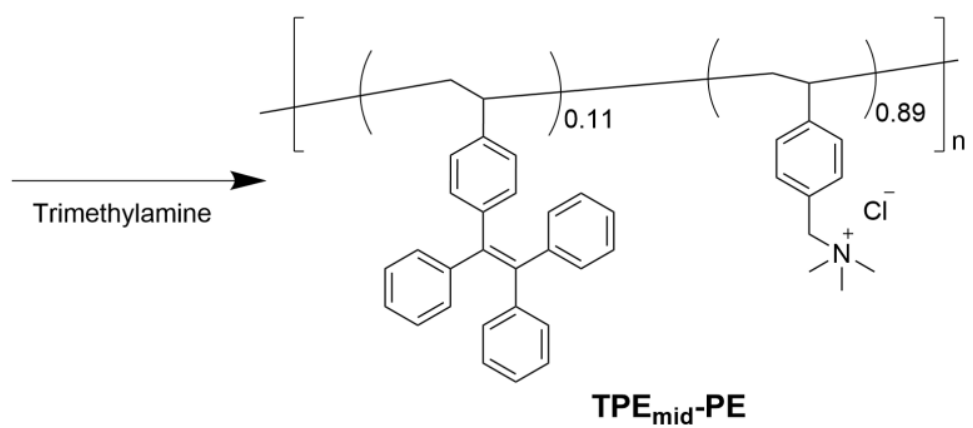

In a $10 \mathrm{~mL}$ pear flask, the precursor (2) was dissolved in trimethylamine (25\% in methanol) (5.0 $\mathrm{mL})$. The reaction mixture was stirred at room temperature for $13 \mathrm{~h}$. The solvent was evaporated, washed with methanol (five times), and then dried in vacuo to afford TPE $\mathbf{m i d}_{-} \mathbf{P E}$ (35.7 $\mathrm{mg}, 0.147 \mathrm{mmol}$ in monomer unit) as a white solid. ${ }^{1} \mathrm{H}$ NMR (400 MHz, DMSO- $\left.d_{6}\right)$ : $\delta_{\mathrm{H}} 7.73-6.81$ (br, $\left.19 \mathrm{H}\right), 6.71-5.88$ (br, 3H), 5.21-4.31 (br, 58H), 2.02-0.41 (br, 20H); ${ }^{13} \mathrm{C}$ NMR (100 MHz, DMSO- $\left.d_{6}\right)$ : $\delta_{\mathrm{C}} 133.0,130.1$, 127.9, 66.9, 51.5; IR $v 3852,3818,3727,3707,3626,3599,3349,2966,2276,2203,2178,2163$, 2141, 2051, 1990, 1979, 1771, 1716, 1698, 1684, 1653, 1635, 1558, 1541, 1507, 1474, 1456, 1418, 1261, 1055, 1033, 1017, 923, 889, 857, 822, 720, 669, 658, $617 \mathrm{~cm}^{-1}$. The DS (x) of TPEmid-PE was

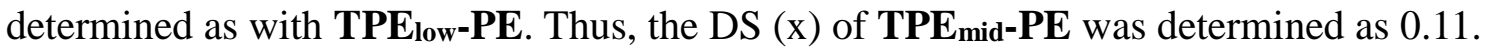

(a)

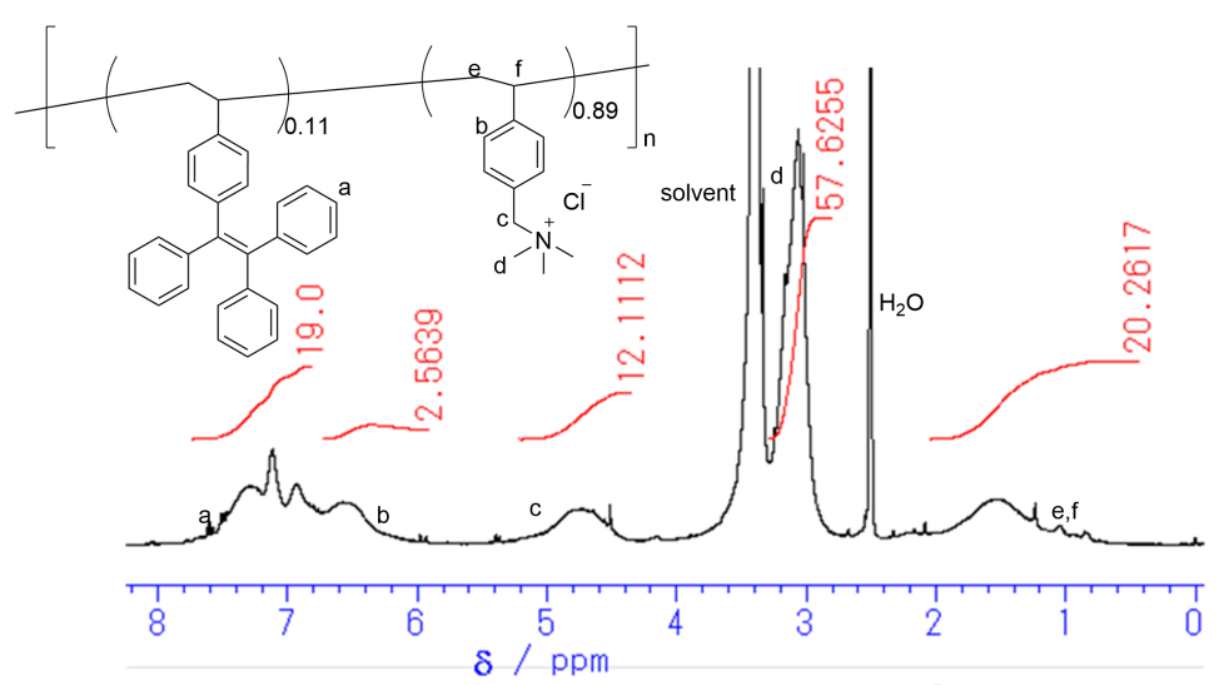

(b)
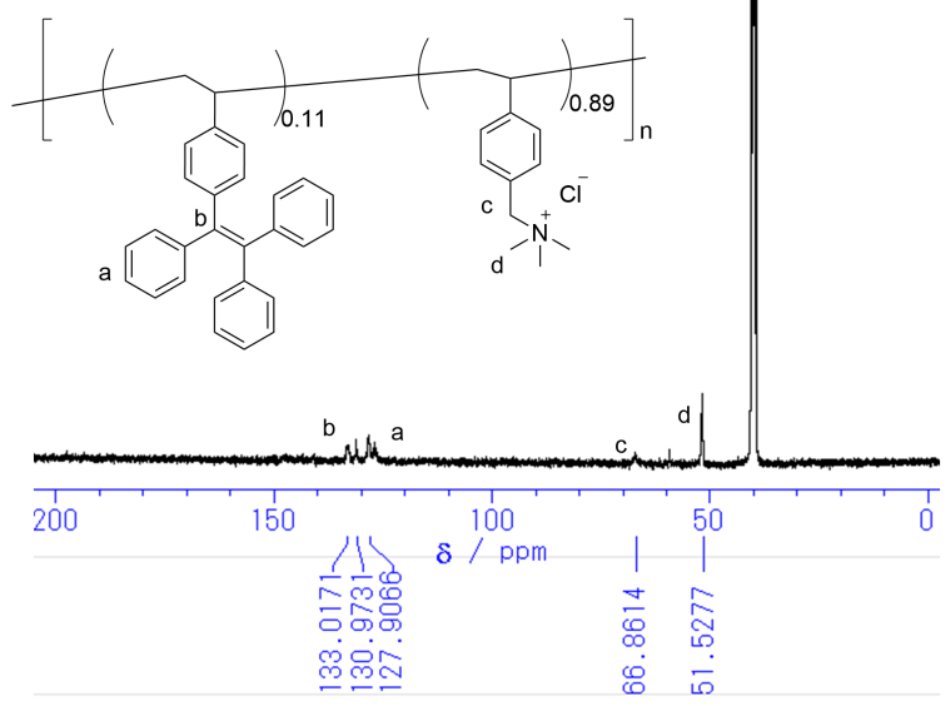

Figure S8. (a) ${ }^{1} \mathrm{H}(400 \mathrm{MHz})$ and (b) ${ }^{13} \mathrm{C}$ NMR (100 MHz) spectra of TPEmid-PE in DMSO- $d 6$. 


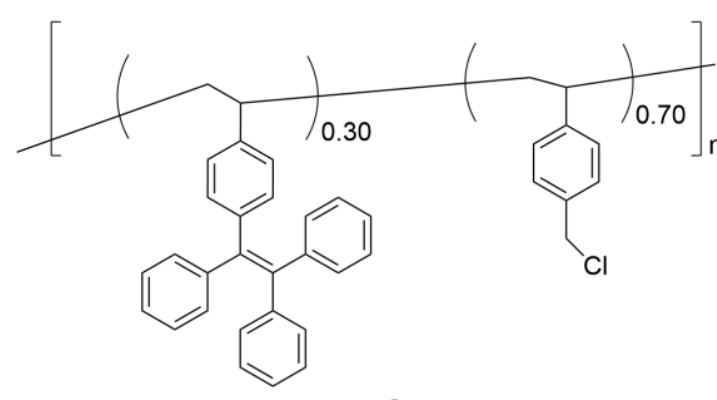

3

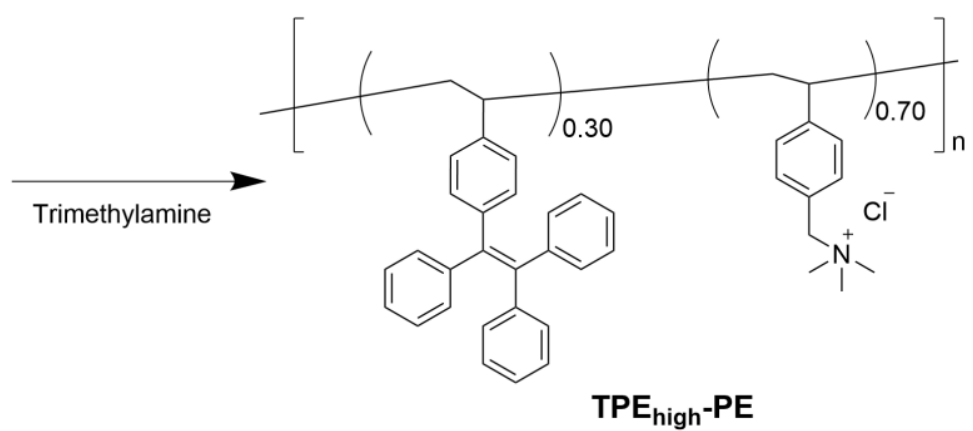

In a $10 \mathrm{~mL}$ pear flask, the precursor (3) was dissolved in trimethylamine (25\% in methanol) $(5.0 \mathrm{~mL})$. The reaction mixture was stirred at room temperature for $13 \mathrm{~h}$. The solvent was evaporated, washed with methanol (five times), and then dried in vacuo to afford TPEhigh-PE (22.4 $\mathrm{mg}, 0.0830 \mathrm{mmol}$ in monomer unit) as a white solid. ${ }^{1} \mathrm{H}$ NMR (400 MHz, DMSO- $\left.d_{6}\right)$ : $\delta_{\mathrm{H}} 7.61-6.57$ (br, 19H), 6.50-5.93 (br, 1H), 5.25-4.19 (br, 1H), 3.32-2.84 (br, 10H), 2.26-0.997 (br, 5H); ${ }^{13} \mathrm{C}$ NMR (100 MHz, DMSO-d6): $\delta_{\mathrm{C}} 131.1,128.3,58.8,51.9$; IR $v 3723,3707,3626,3599,5966,2866,2843,2360,2165$, 2140, 2113, 2077, 2051, 2011, 1980, 1791, 1259, 1055, 1033, 1014, 796, 720, 669, 658, $617 \mathrm{~cm}^{-1}$.

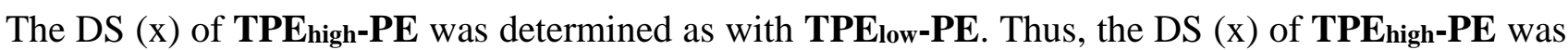
determined as 0.30 .

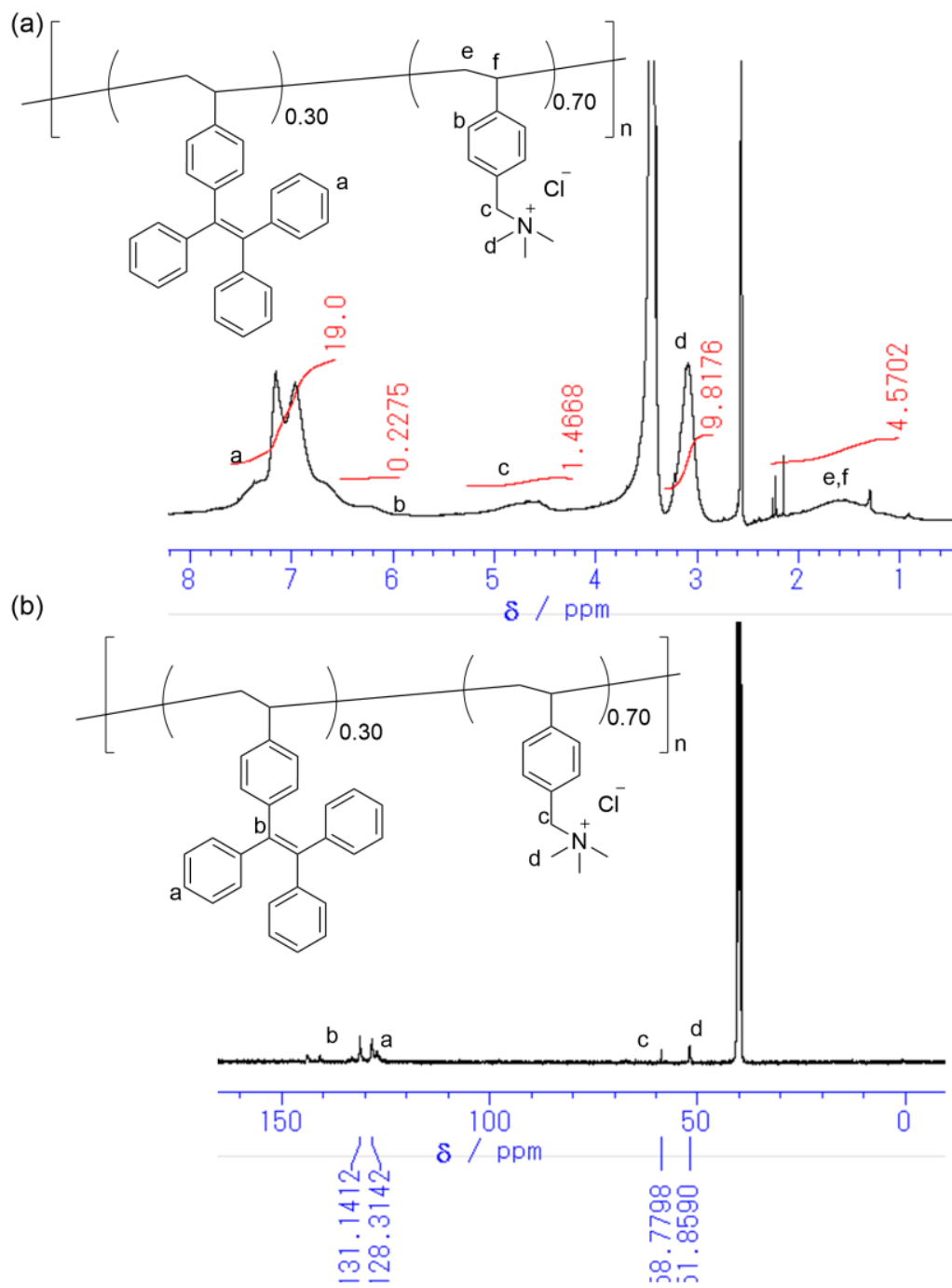

Figure S9. (a) ${ }^{1} \mathrm{H}(400 \mathrm{MHz})$ and (b) ${ }^{13} \mathrm{C}$ NMR (100 MHz) spectra of TPEhigh-PE in DMSO-d6. 
(a)

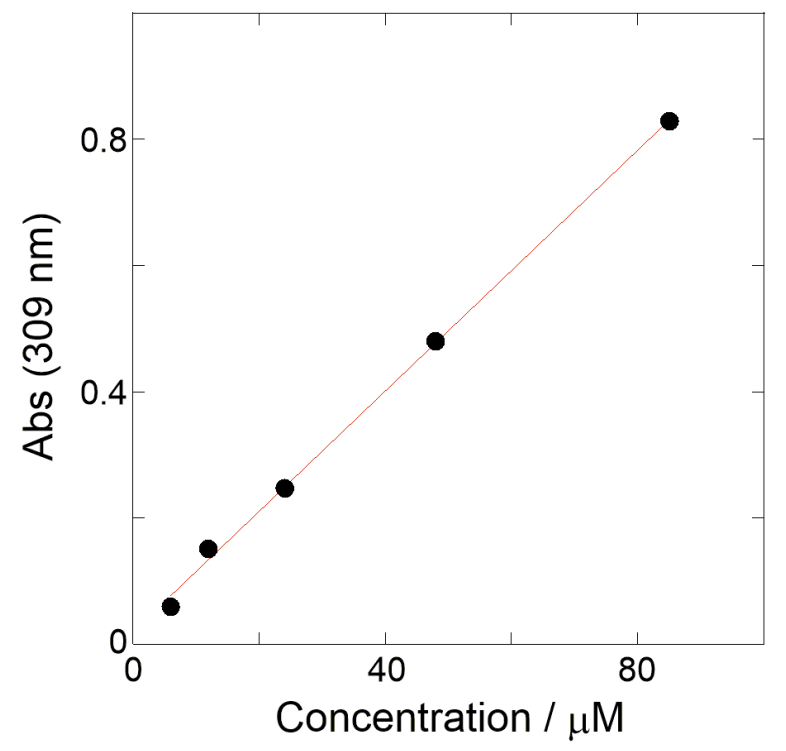

(b)

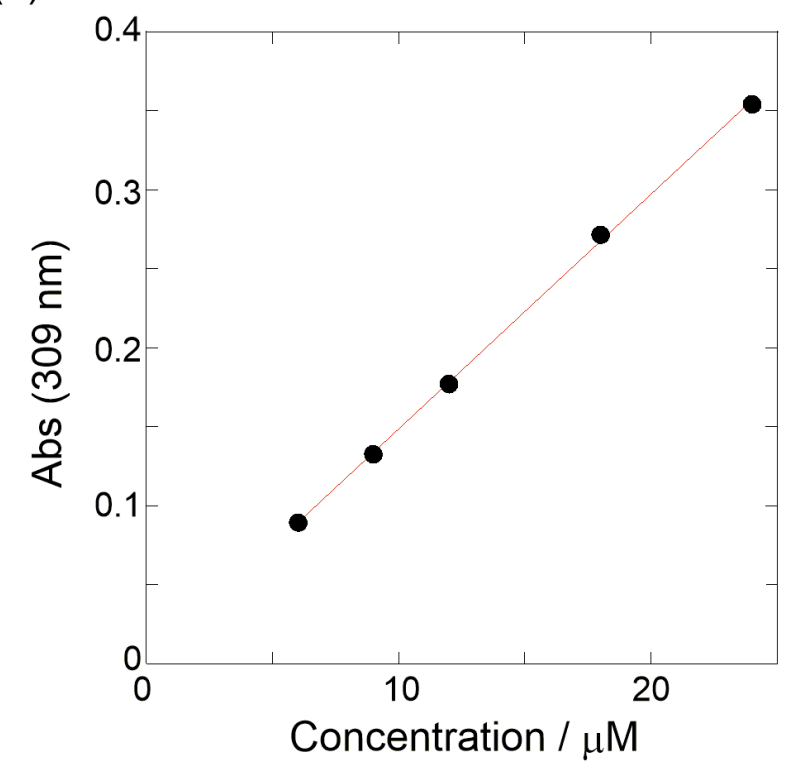

Figure S10. Concentration-dependent absorbance changes at $309 \mathrm{~nm}$ of (a) TPE mid-PE (correlation

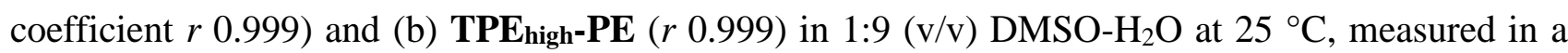
$1-\mathrm{cm}$ cell.

\section{DLS Measurements}

(a)

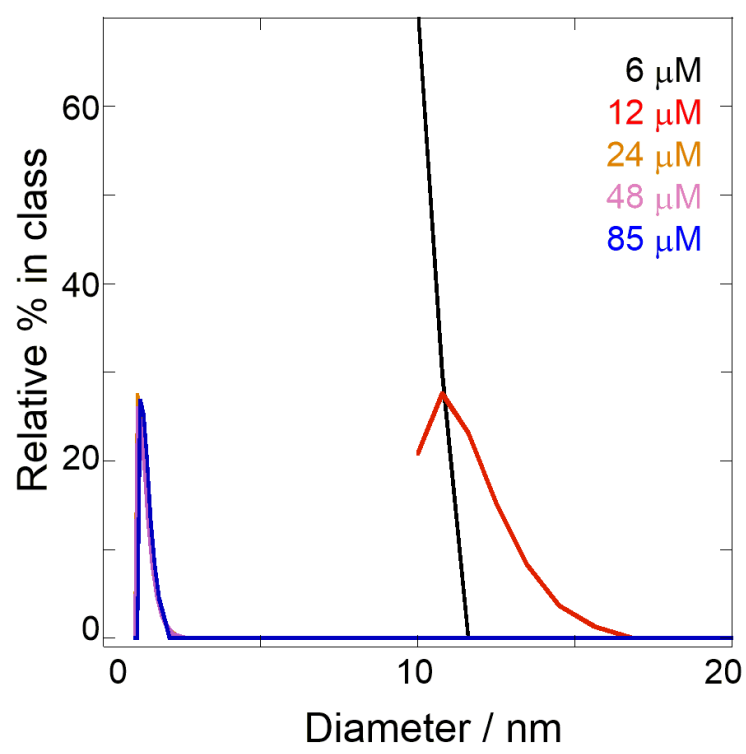

(b)

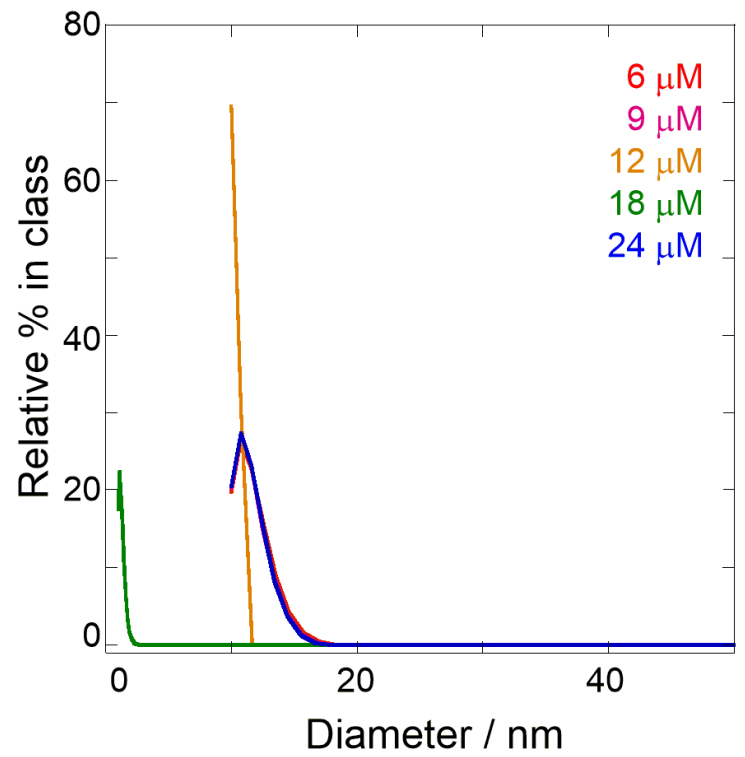

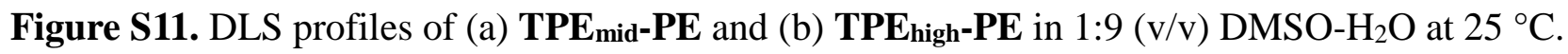




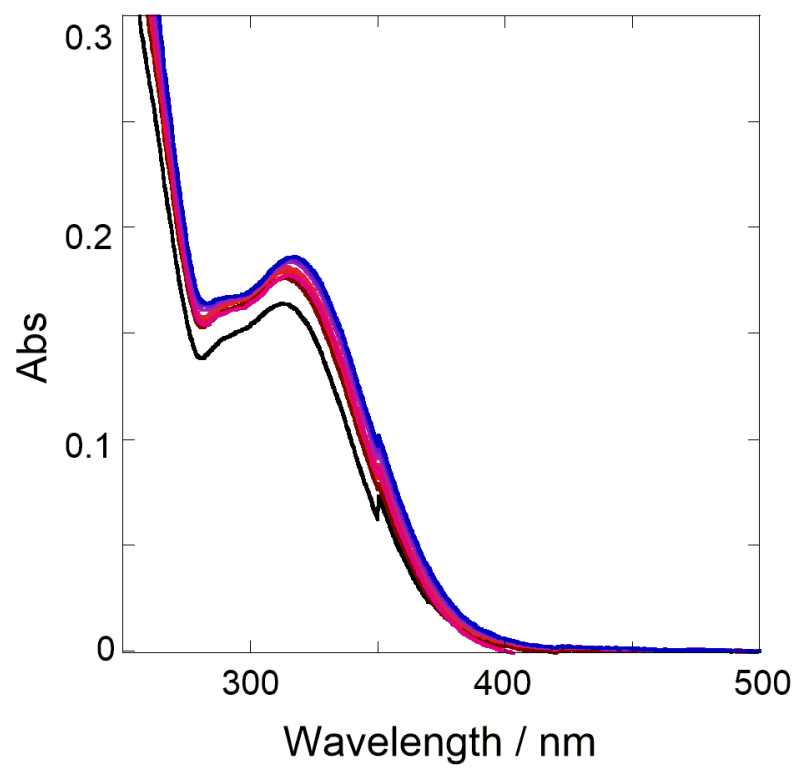

Figure S12. UV/vis spectra of a $1: 9(\mathrm{v} / \mathrm{v})$ DMSO- $\mathrm{H}_{2} \mathrm{O}$ solution of TPElow-PE (74 $\mu \mathrm{M}$ in chromophore unit) at $0.1,40,80,120,160,200,240$, and $280 \mathrm{MPa}$ (from black to blue lines) at room temperature in a high-pressure cell. 


\section{Table S1. Fluorescence Lifetimes of DPP and TPE-PEs ${ }^{a}$}

\begin{tabular}{|c|c|c|c|c|c|c|c|c|}
\hline Compd. & $\mathrm{MPa}$ & $\lambda_{\mathrm{em}}^{b}$ & $n^{c}$ & $\tau_{1}$ & $A_{1}$ & $\tau_{2}$ & $A_{2}$ & $\chi^{2}$ \\
\hline $\mathrm{DPP}^{d}$ & 0.1 & 380 & 2 & 0.2 & 0.52 & $5.3^{e}$ & 0.48 & 1.0 \\
\hline \multirow[t]{16}{*}{ TPElow-PE } & 0.1 & 380 & 2 & 0.1 & 0.66 & 1.5 & 0.34 & 1.1 \\
\hline & & 510 & 2 & 0.1 & 0.24 & 1.8 & 0.76 & 1.1 \\
\hline & 40 & 380 & 2 & 0.1 & 0.64 & 2.6 & 0.36 & 1.2 \\
\hline & & 510 & 2 & 0.1 & 0.21 & 1.6 & 0.79 & 1.0 \\
\hline & 80 & 380 & 2 & 0.1 & 0.63 & 1.3 & 0.37 & 1.2 \\
\hline & & 510 & 2 & 0.3 & 0.27 & 2.9 & 0.73 & 1.1 \\
\hline & 120 & 380 & 2 & 0.1 & 0.53 & 3.4 & 0.47 & 1.2 \\
\hline & & 510 & 2 & 0.1 & 0.23 & 2.5 & 0.77 & 1.1 \\
\hline & 160 & 380 & 2 & 0.1 & 0.62 & 1.6 & 0.38 & 1.2 \\
\hline & & 510 & 2 & 0.1 & 0.20 & 2.0 & 0.80 & 0.8 \\
\hline & 200 & 380 & 2 & 0.1 & 0.61 & 1.7 & 0.39 & 1.0 \\
\hline & & 510 & 2 & 0.3 & 0.25 & 3.2 & 0.75 & 1.0 \\
\hline & 240 & 380 & 2 & 0.1 & 0.59 & 1.4 & 0.41 & 1.2 \\
\hline & & 510 & 2 & 0.3 & 0.24 & 3.2 & 0.76 & 1.2 \\
\hline & 280 & 380 & 2 & 0.1 & 0.51 & 1.4 & 0.49 & 1.2 \\
\hline & & 510 & 2 & 0.1 & 0.20 & 2.5 & 0.80 & 1.2 \\
\hline \multirow[t]{16}{*}{ TPE $_{\text {mid }}-\mathbf{P E}$} & 0.1 & 380 & 2 & 0.1 & 0.70 & 1.6 & 0.30 & 1.1 \\
\hline & & 510 & 2 & 0.3 & 0.31 & 2.6 & 0.69 & 1.1 \\
\hline & 40 & 380 & 2 & 0.1 & 0.70 & 1.6 & 0.30 & 1.2 \\
\hline & & 510 & 2 & 0.3 & 0.25 & 2.3 & 0.75 & 1.2 \\
\hline & 80 & 380 & 2 & 0.1 & 0.67 & 1.6 & 0.33 & 1.0 \\
\hline & & 510 & 2 & 0.1 & 0.16 & 1.9 & 0.84 & 1.2 \\
\hline & 120 & 380 & 2 & 0.1 & 0.66 & 1.7 & 0.34 & 1.2 \\
\hline & & 510 & 2 & 0.1 & 0.17 & 2.2 & 0.83 & 1.1 \\
\hline & 160 & 380 & 2 & 0.1 & 0.65 & 2.9 & 0.35 & 1.2 \\
\hline & & 510 & 2 & 0.4 & 0.21 & 3.0 & 0.79 & 1.0 \\
\hline & 200 & 380 & 2 & 0.1 & 0.64 & 1.5 & 0.36 & 1.1 \\
\hline & & 510 & 2 & 0.4 & 0.19 & 3.0 & 0.81 & 1.0 \\
\hline & 240 & 380 & 2 & 0.1 & 0.63 & 1.7 & 0.37 & 1.0 \\
\hline & & 510 & 2 & 0.1 & 0.14 & 2.7 & 0.86 & 1.0 \\
\hline & 280 & 380 & 2 & 0.1 & 0.62 & 1.5 & 0.38 & 1.0 \\
\hline & & 510 & 2 & 0.1 & 0.13 & 2.8 & 0.87 & 1.1 \\
\hline \multirow[t]{5}{*}{ TPEhigh-PE ${ }^{g}$} & 0.1 & 510 & 2 & 0.1 & 0.09 & 2.6 & 0.91 & 1.2 \\
\hline & 40 & 510 & 2 & 0.1 & 0.09 & 2.7 & 0.91 & 1.0 \\
\hline & 80 & 510 & 2 & 0.1 & 0.08 & 2.8 & 0.92 & 1.1 \\
\hline & 120 & 510 & 2 & 0.1 & 0.07 & 2.6 & 0.93 & 1.1 \\
\hline & 160 & 510 & 2 & 0.1 & 0.08 & 2.8 & 0.92 & 1.2 \\
\hline
\end{tabular}




$\begin{array}{llllllll}200 & 510 & 2 & 0.1 & 0.07 & 2.8 & 0.93 & 0.9 \\ 240 & 510 & 2 & 0.1 & 0.08 & 3.0 & 0.92 & 1.2 \\ 280 & 510 & 2 & 0.1 & 0.07 & 2.8 & 0.93 & 0.9\end{array}$

${ }^{a}$ Fluorescence lifetime $\left(\tau_{\mathrm{i}} / \mathrm{ns}\right)$ and relative abundance $\left(A_{\mathrm{i}}\right)$ of each excited component in a non-degassed 1:9 (v/v) DMSO- $\mathrm{H}_{2} \mathrm{O}$ solution at room temperature, measured in a high-pressure cell unless noted otherwise. ${ }^{b}$ Monitoring wavelength (nm). ${ }^{c}$ Number of components. ${ }^{d}$ Measured in a $1-\mathrm{cm}$ cell. ${ }^{e}$ The excited species is assignable to an excimer. 
(a)
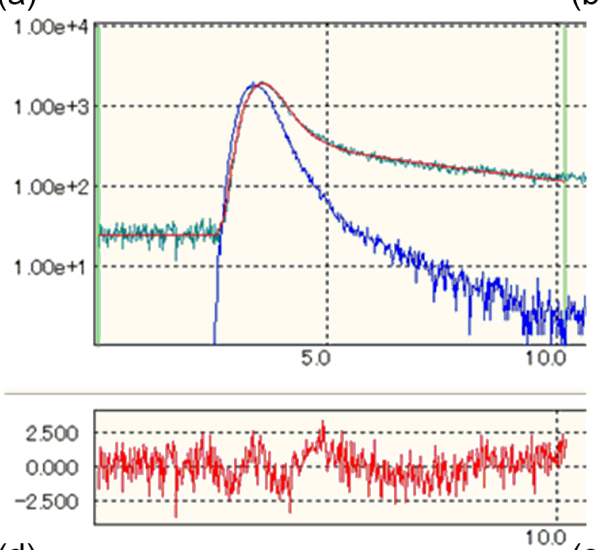

(d)
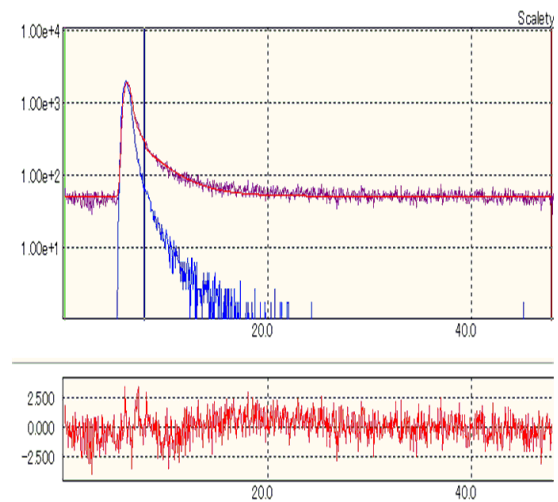

(g)
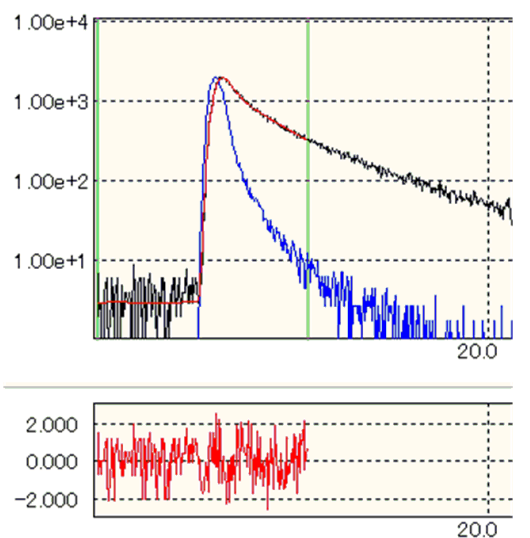

(b)
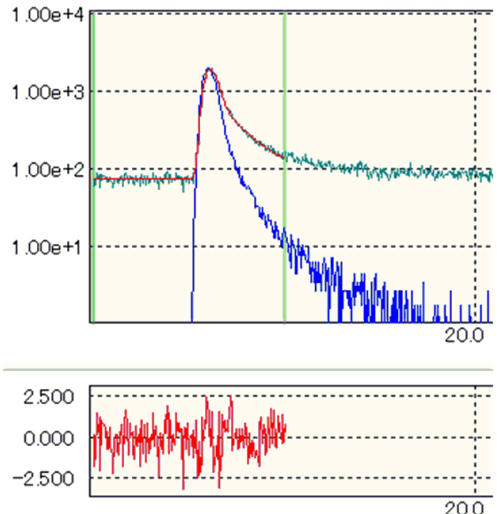

(e)
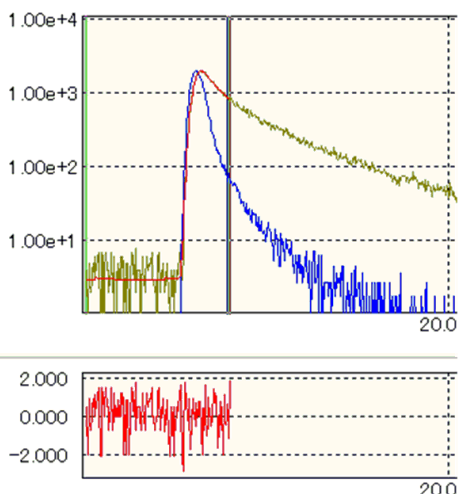

(h)
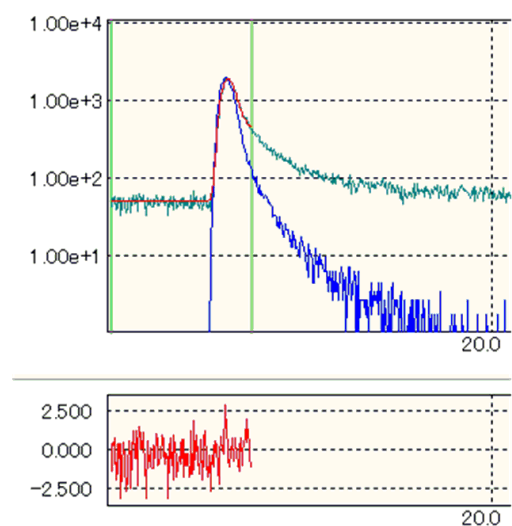

(c)

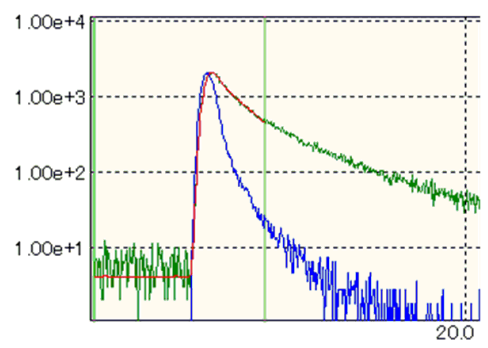

$2 0 0 0 \longdiv { - 1 0 0 0 }$

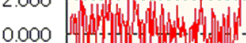

-2.000 年

(f)

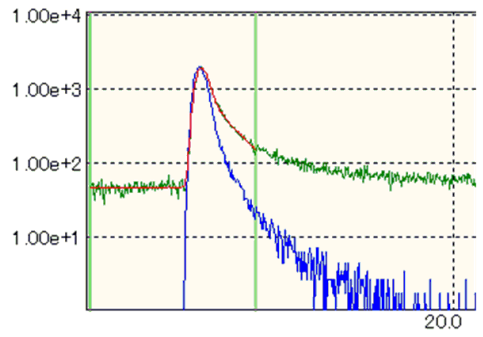

2.500

0.000 Anth

-2.500 f

(i)
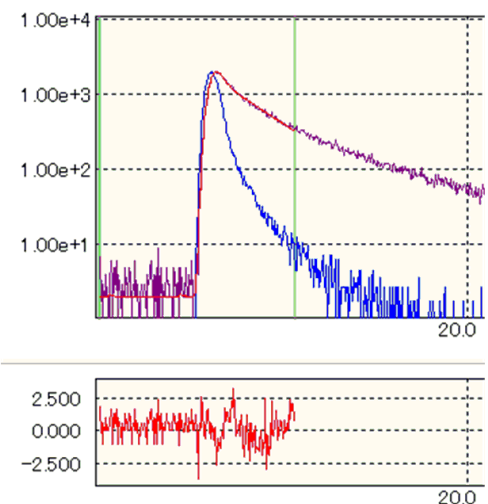
(j)
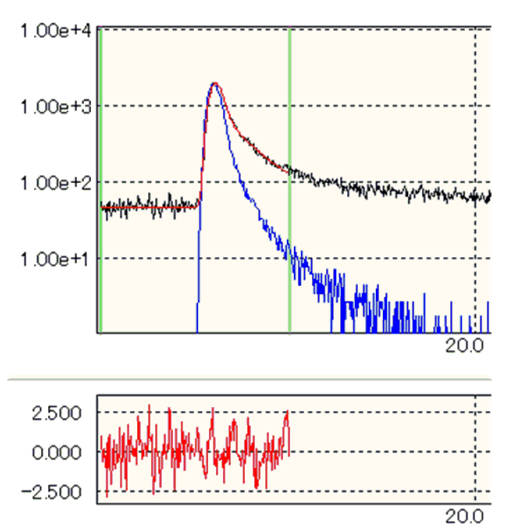

(m)
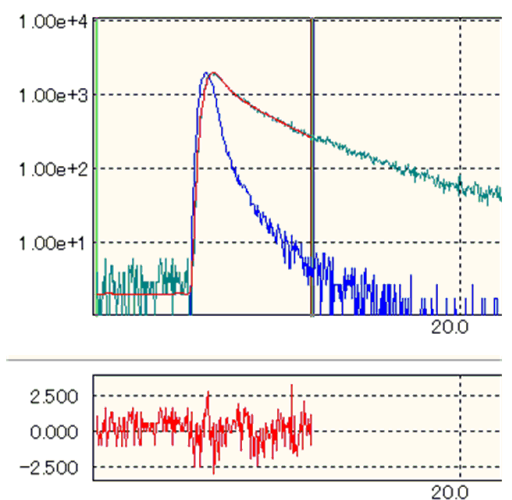

(p)
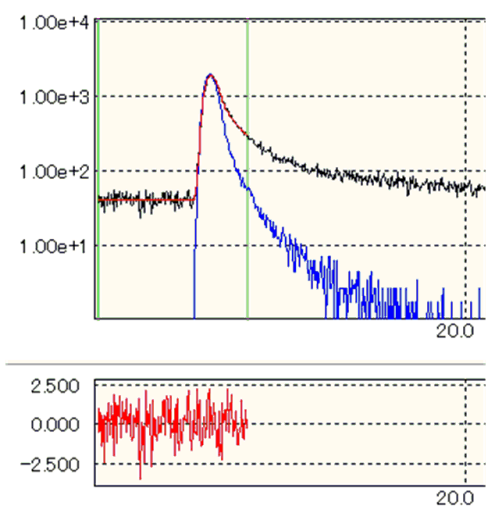

(k)
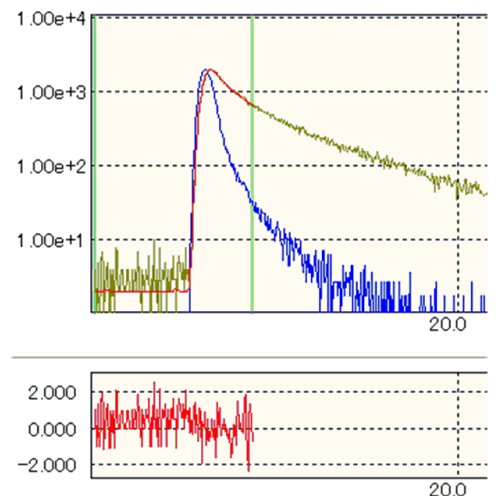

(n)
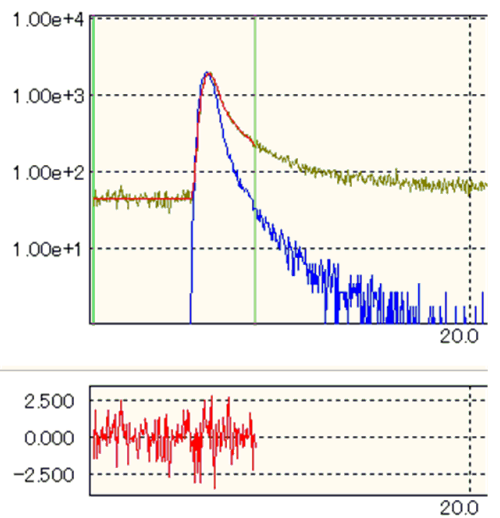

(q)

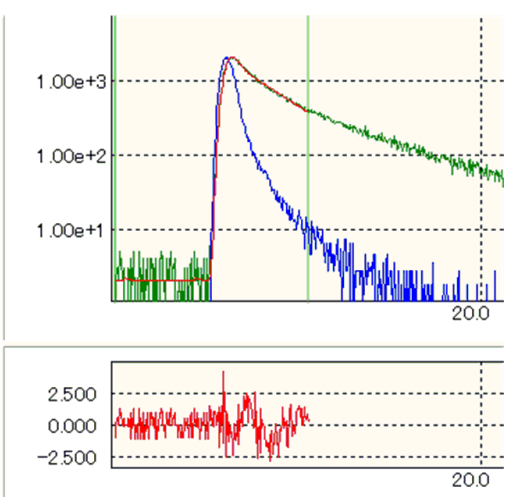

(I)
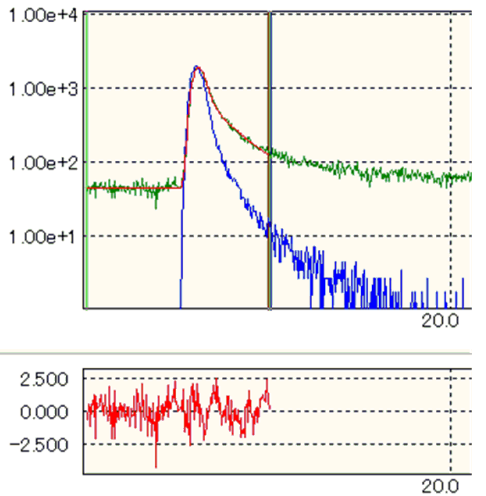

(o)
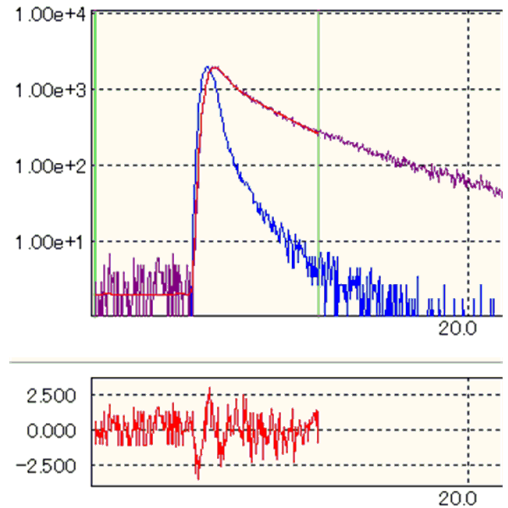

Figure S13. Time-correlated fluorescence decays of (a) DPP $(9.8 \mu \mathrm{M})$ monitored at $380 \mathrm{~nm}$ (measured in a 1-cm cell) and (b-q) TPElow-PE $(9.0 \mu \mathrm{M})$ monitored at (b) 380 and (c) $510 \mathrm{~nm}$ at 0.1 $\mathrm{MPa}$, (d) 380 and (e) $510 \mathrm{~nm}$ at $40 \mathrm{MPa}$, (f) 380 and (g) $510 \mathrm{~nm}$ at $80 \mathrm{MPa}$, (h) 380 and (i) $510 \mathrm{~nm}$ at $120 \mathrm{MPa}$, (j) 380 and (k) $510 \mathrm{~nm}$ at $160 \mathrm{MPa}$, (l) 380 and (m) $510 \mathrm{~nm}$ at $200 \mathrm{MPa}$, (n) 380 and (o) $510 \mathrm{~nm}$ at $240 \mathrm{MPa}$, and (p) 380 and (q) $510 \mathrm{~nm}$ at $280 \mathrm{MPa}$ in 1:9 (v/v) DMSO- $\mathrm{H}_{2} \mathrm{O}$ at room temperature, measured in a high-pressure cell, where the colored, red, and blue lines represent the fluorescence decay, fitting result, and the instrument response function, respectively. 
(a)
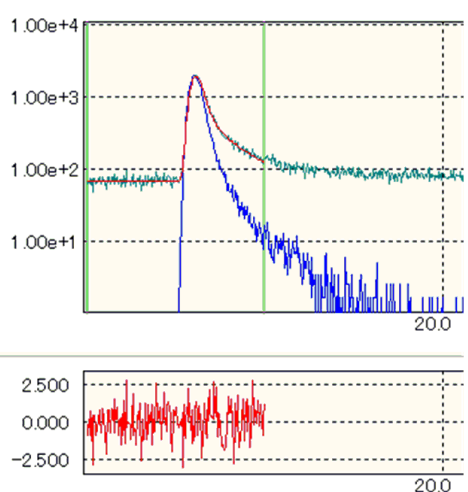

(d)

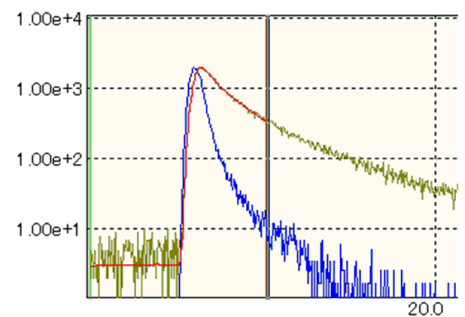

$2 . 0 0 0 \longdiv { 0 }$

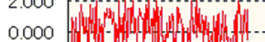

$-2.000$

(g)
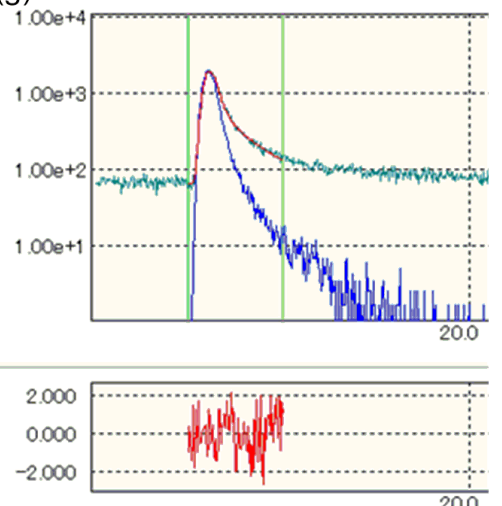

(b)
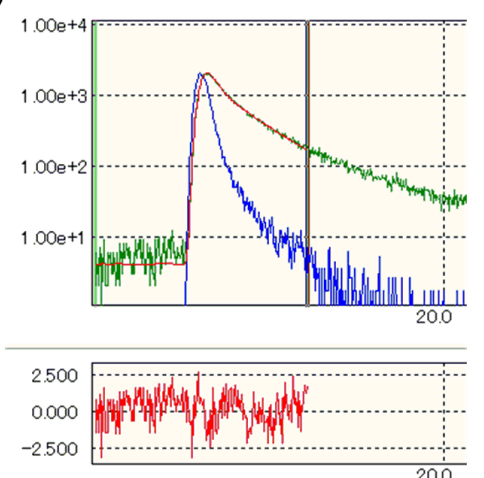

(e)
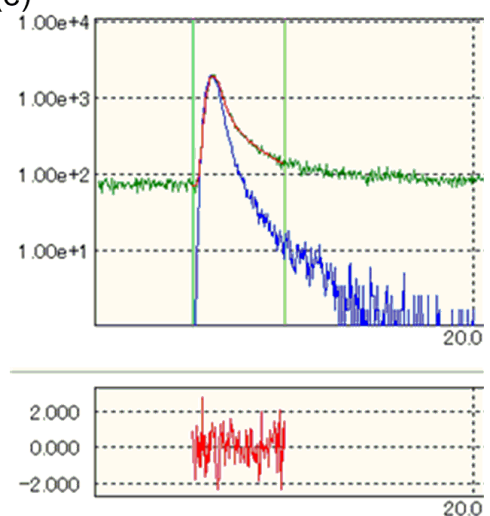

(h)

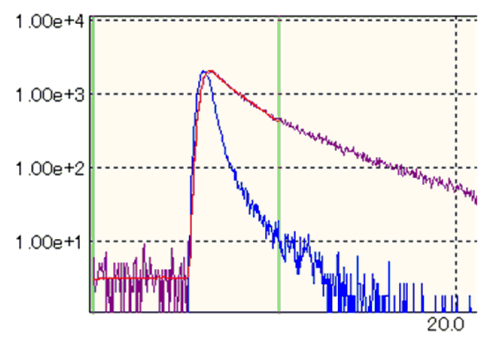

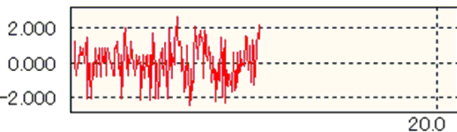

(c)
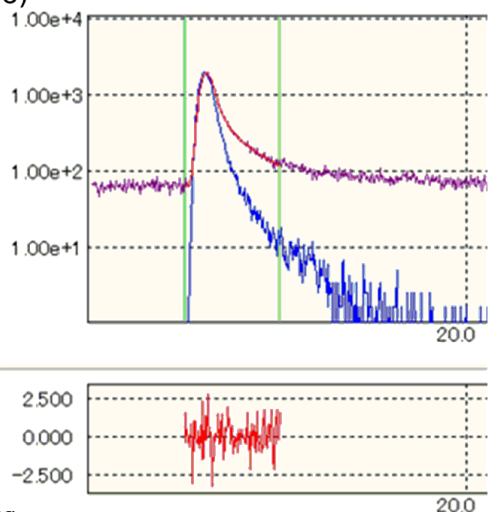

(f)

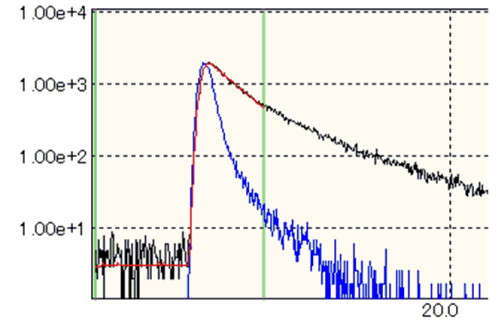

2.500

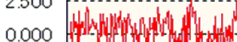

-2.500 Pon

(i)

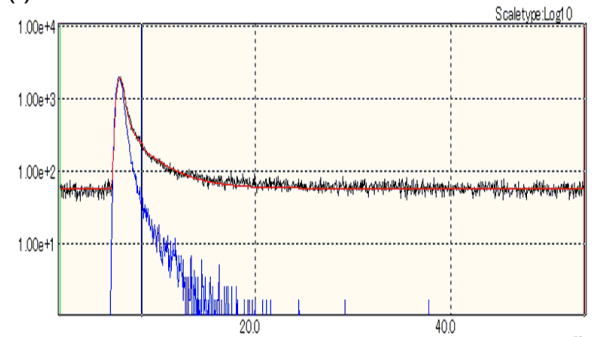

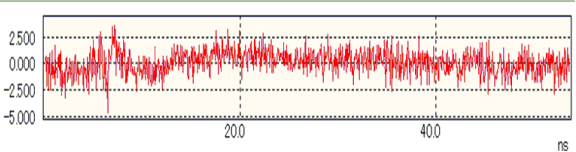


(j)
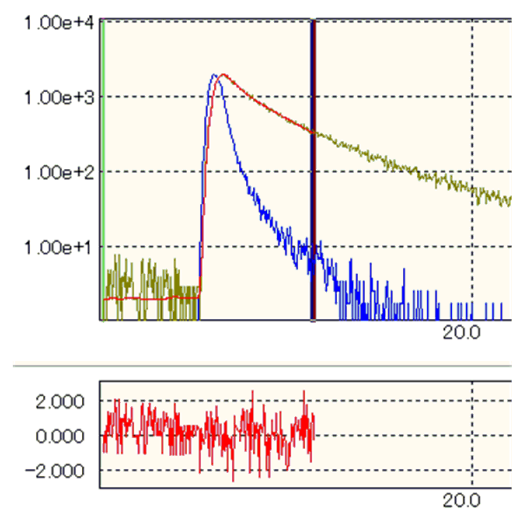

$(\mathrm{m})$
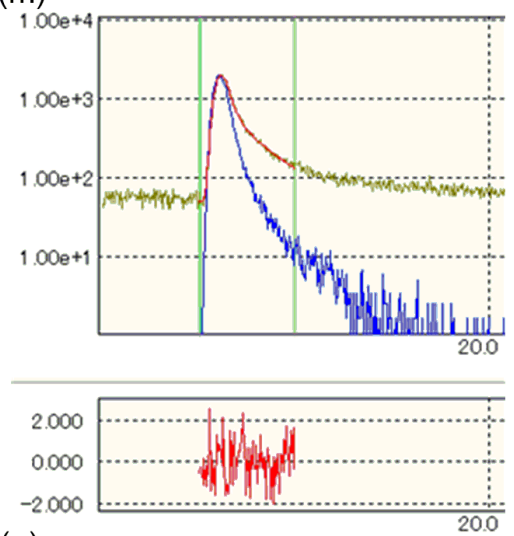

(p)

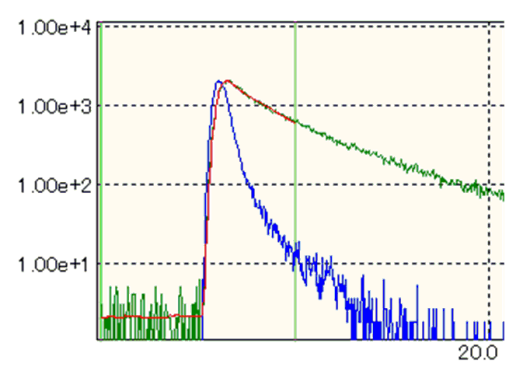

(k)
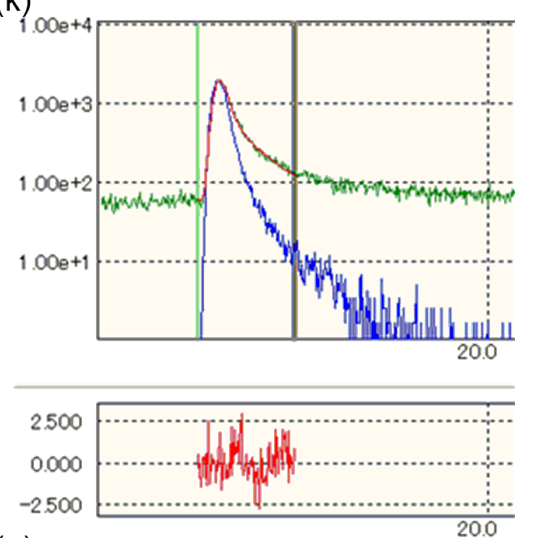

(n)
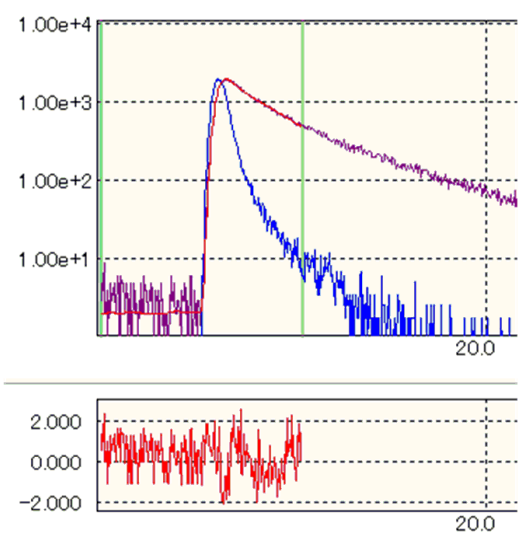

(l)
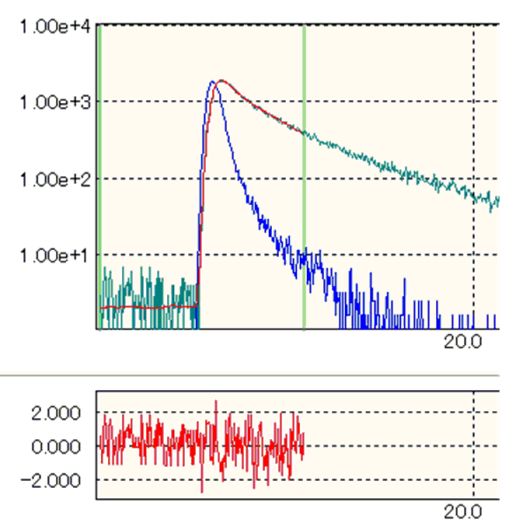

(o)
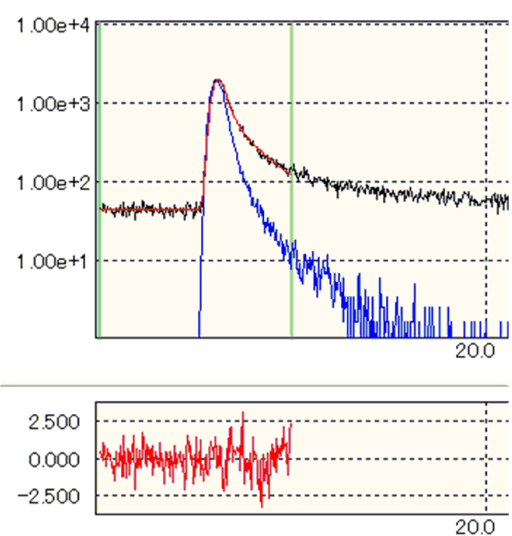

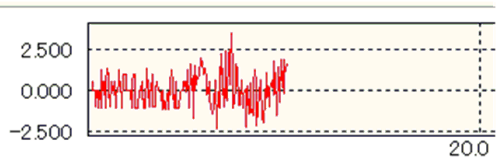

Figure S14. Time-correlated fluorescence decays of TPEmid-PE $(9.0 \mu \mathrm{M})$ monitored at (a) 380 and (b) $510 \mathrm{~nm}$ at $0.1 \mathrm{MPa}$, (c) 380 and (d) $510 \mathrm{~nm}$ at $40 \mathrm{MPa}$, (e) 380 and (f) $510 \mathrm{~nm}$ at $80 \mathrm{MPa}$, (g) 380 and (h) $510 \mathrm{~nm}$ at $120 \mathrm{MPa}$, (i) 380 and (j) $510 \mathrm{~nm}$ at $160 \mathrm{MPa}$, (k) 380 and (l) $510 \mathrm{~nm}$ at 200 $\mathrm{MPa}$, (m) 380 and (n) $510 \mathrm{~nm}$ at $240 \mathrm{MPa}$, and (o) 380 and (p) $510 \mathrm{~nm}$ at $280 \mathrm{MPa}$ in 1:9 (v/v) DMSO- $\mathrm{H}_{2} \mathrm{O}$ at room temperature, measured in a high-pressure cell, where the colored, red, and blue lines represent the fluorescence decay, fitting result, and the instrument response function, respectively. 
(a)
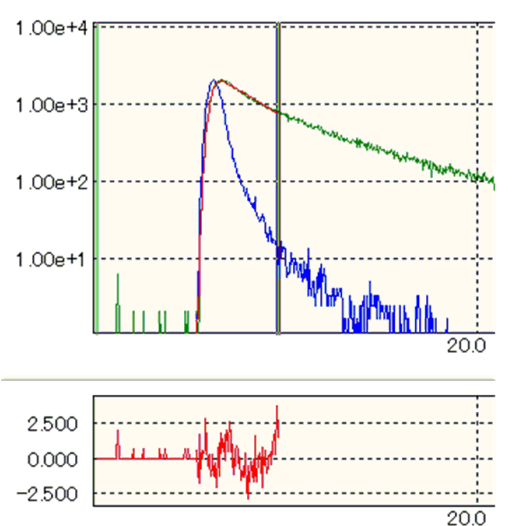

(d)
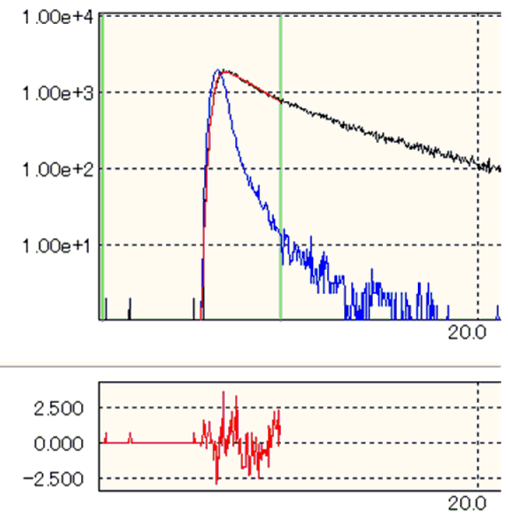

(g)
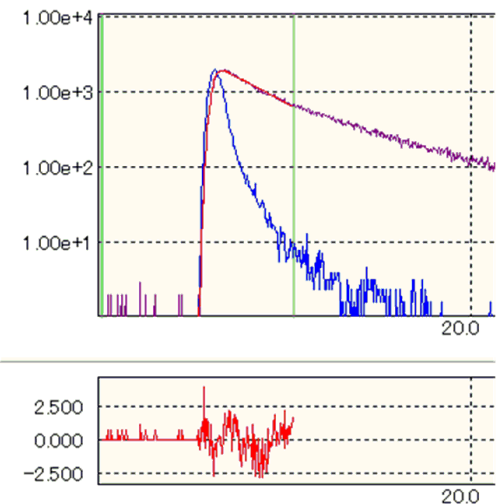

(b)
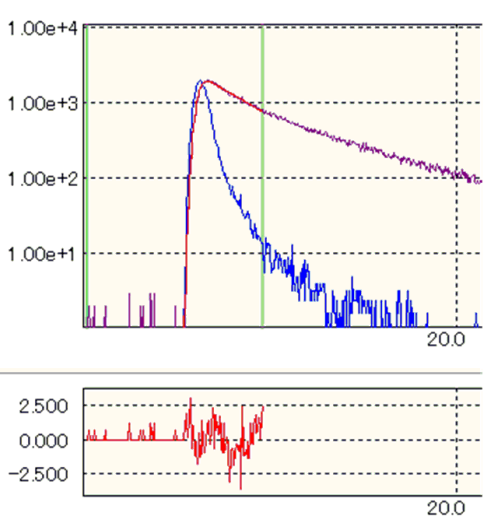

(e)
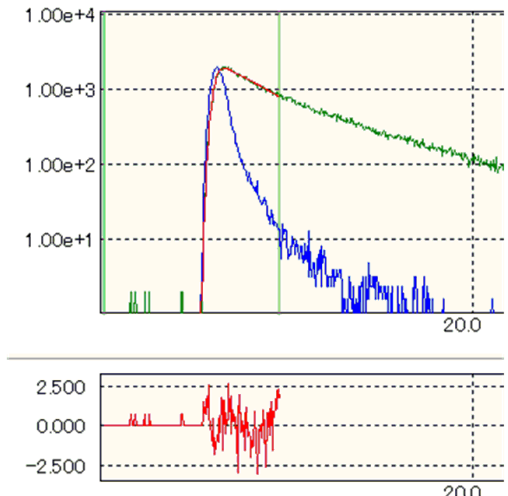

(h)

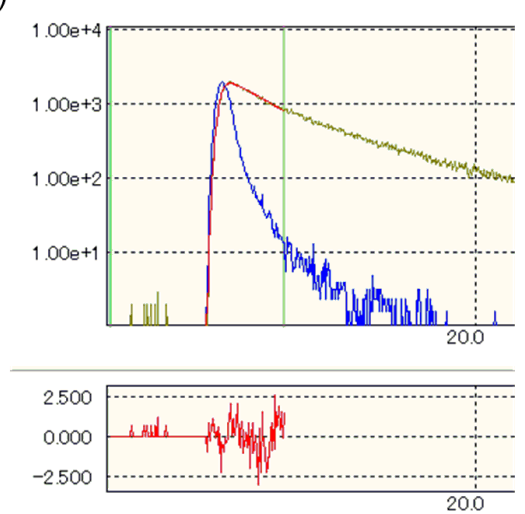

(c)
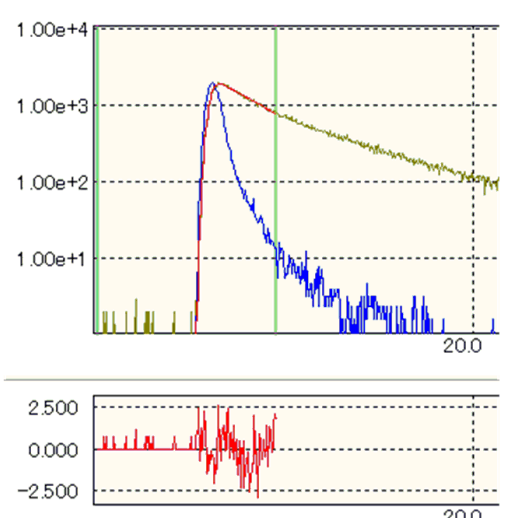

(f)
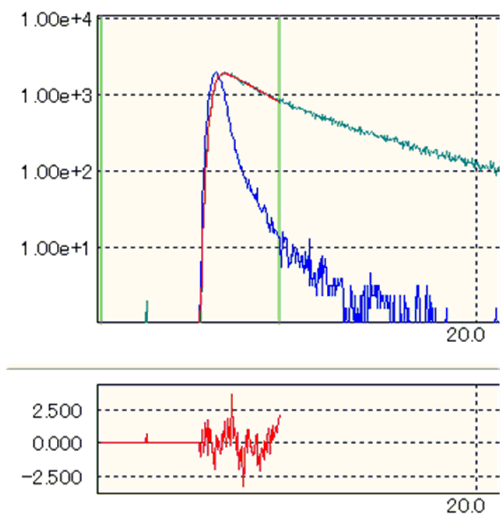

Figure S15. Time-correlated fluorescence decays of TPE (a) $0.1 \mathrm{MPa}$, (b) $40 \mathrm{MPa}$, (c) $80 \mathrm{MPa}$, (d) $120 \mathrm{MPa}$, (e) $160 \mathrm{MPa}$, (f) $200 \mathrm{MPa}$, (g) $240 \mathrm{MPa}$, and (h) $280 \mathrm{MPa}$ in 1:9 (v/v) DMSO- $\mathrm{H}_{2} \mathrm{O}$ at room temperature, measured in a high-pressure cell, where the colored, red, and blue lines represent the fluorescence decay, fitting result, and the instrument response function, respectively. 
(a)

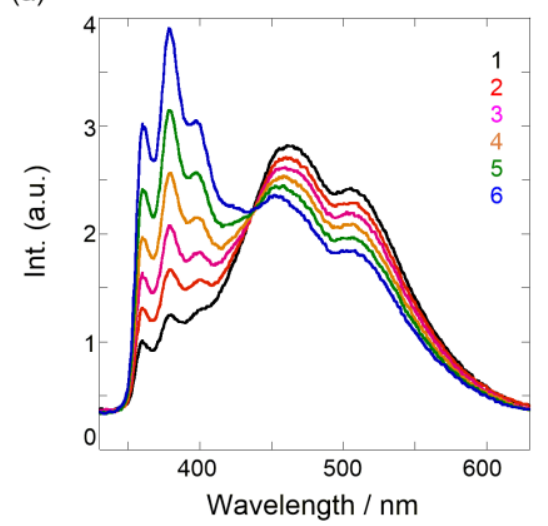

(d)

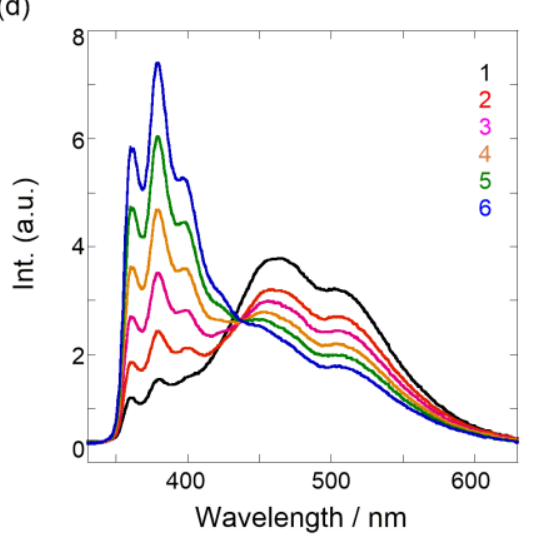

(g)

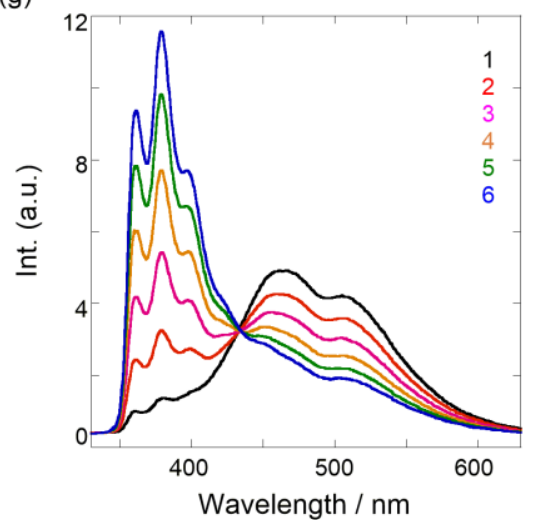

(j)

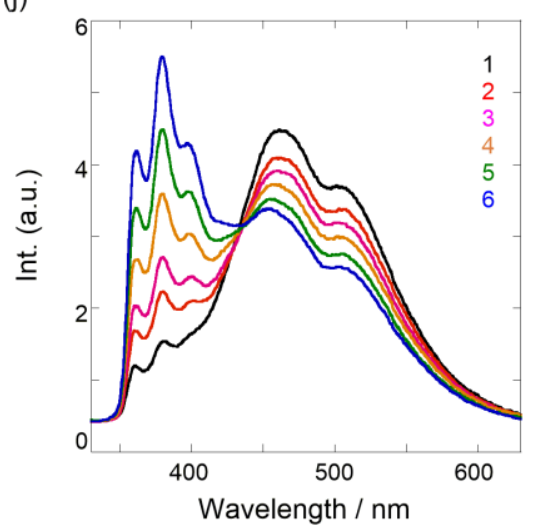

(b)

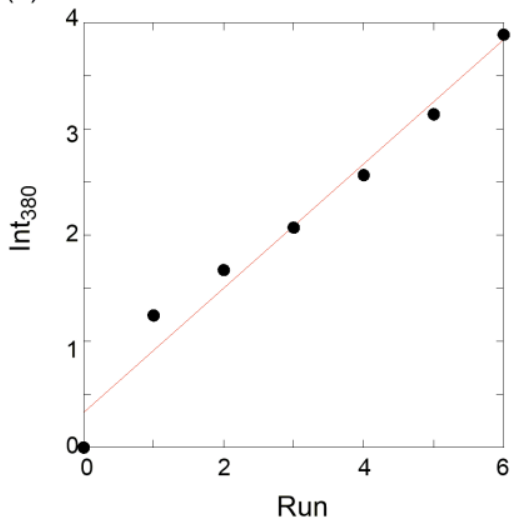

(e)

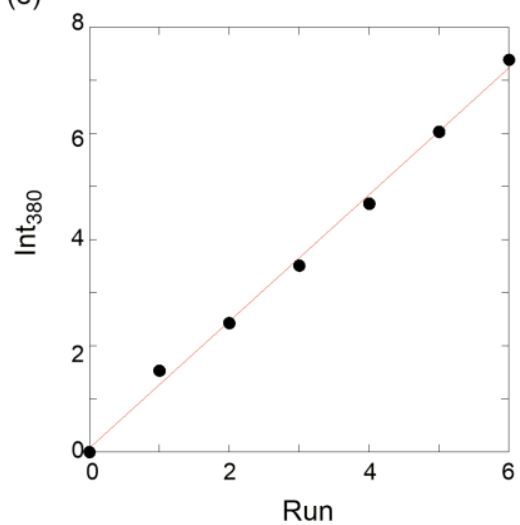

(h)

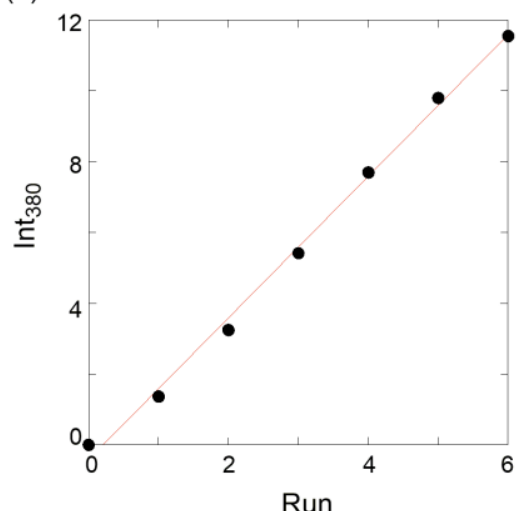

(k)

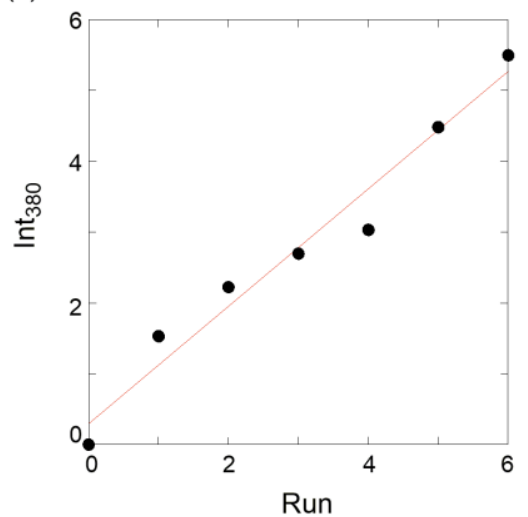

(c)

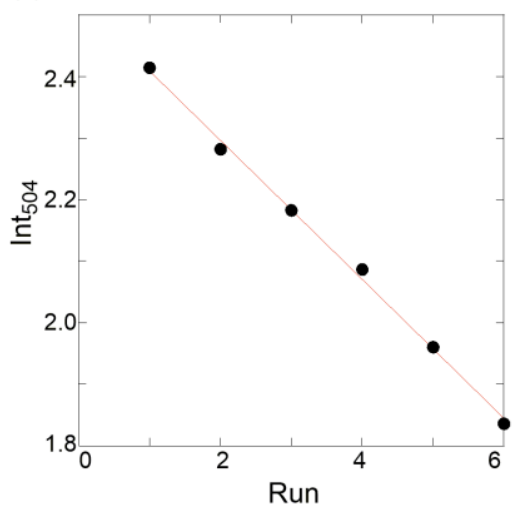

(f)

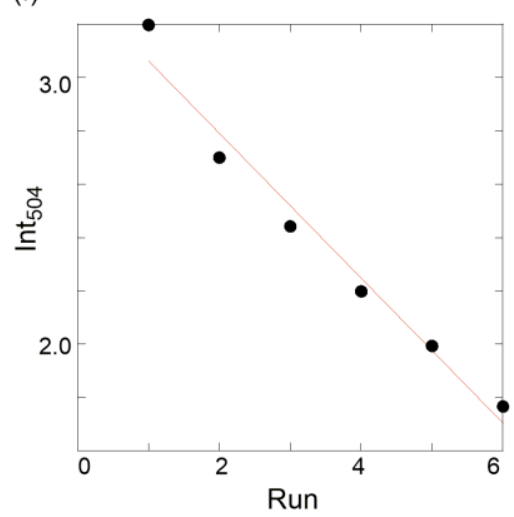

(i)

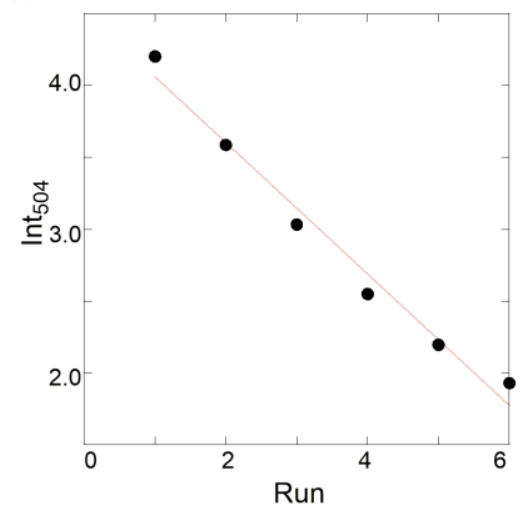

(I)

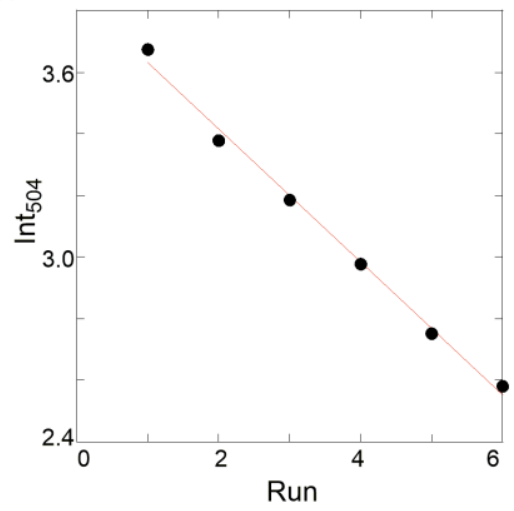


(m)

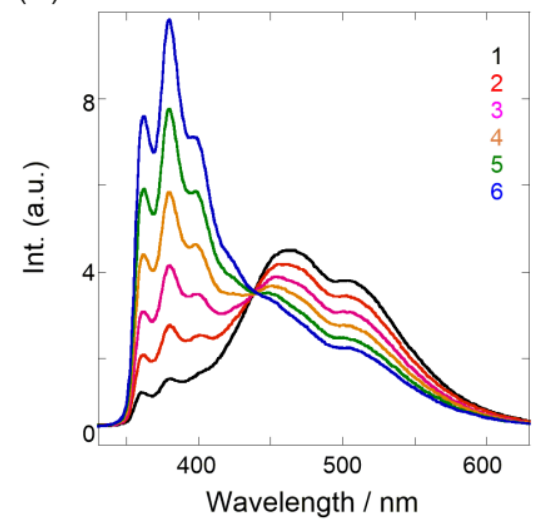

(p)

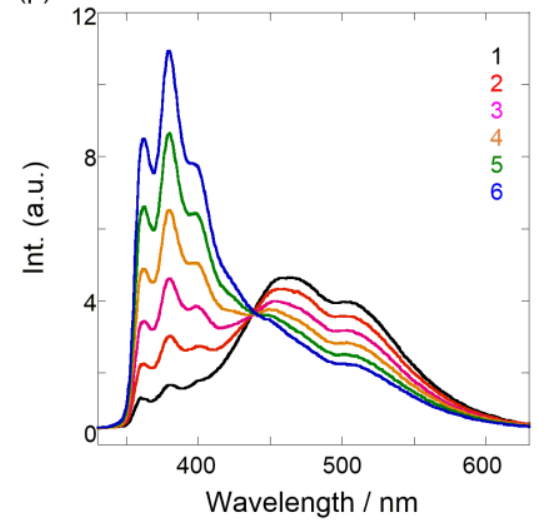

(s)

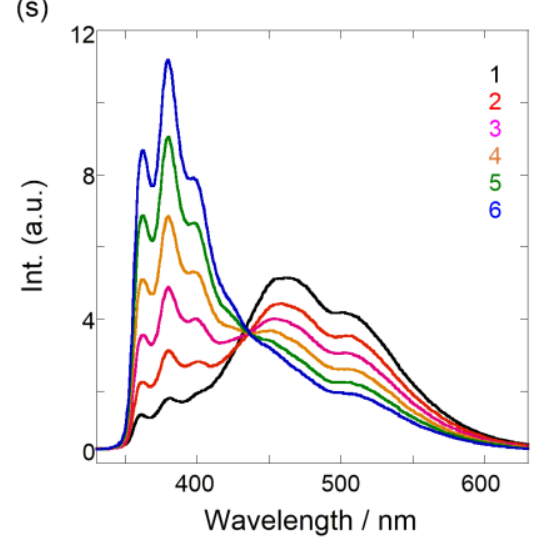

(v)

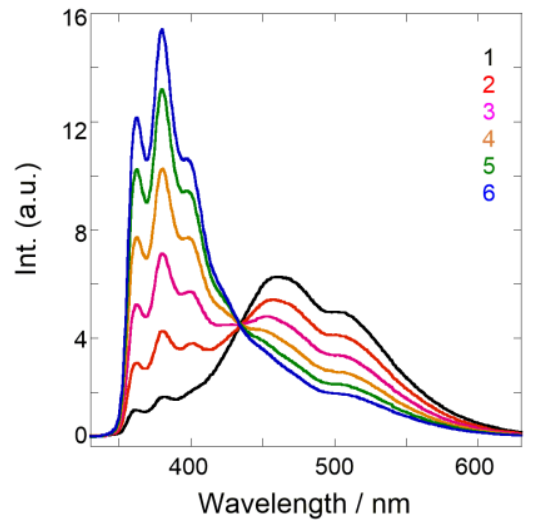

(n)

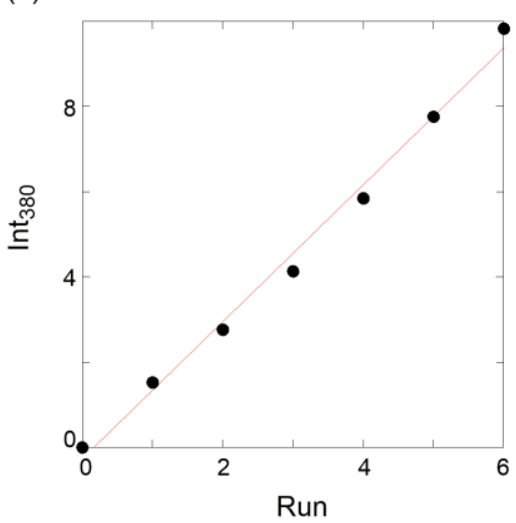

(q)

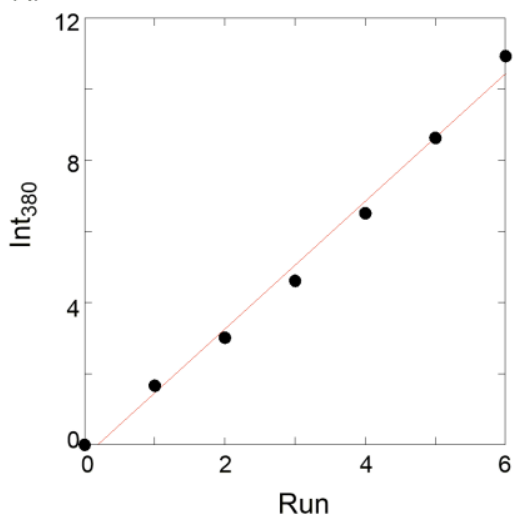

( $\mathrm{t})$

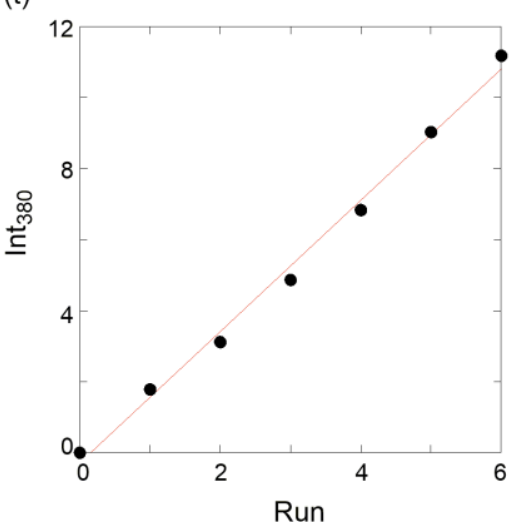

(w)

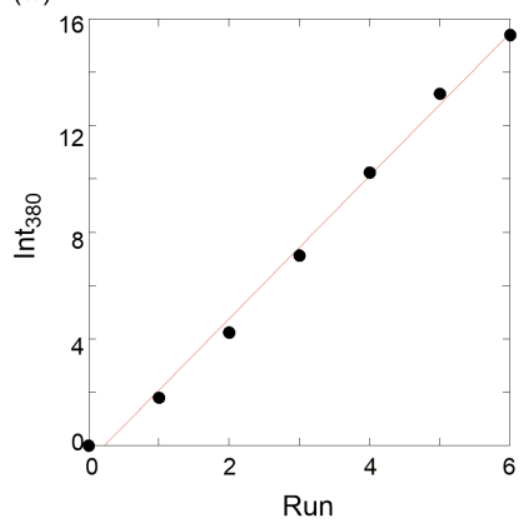

(o)

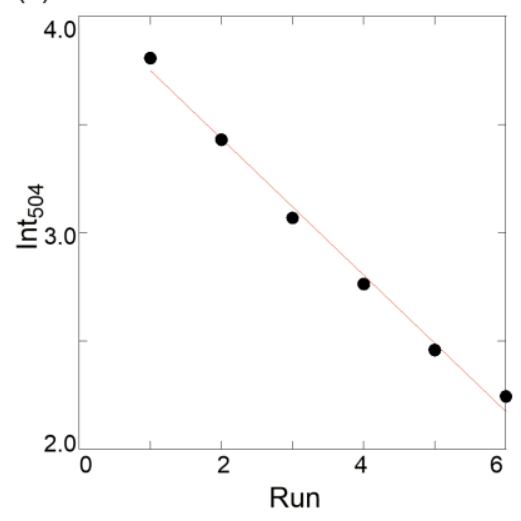

(r)

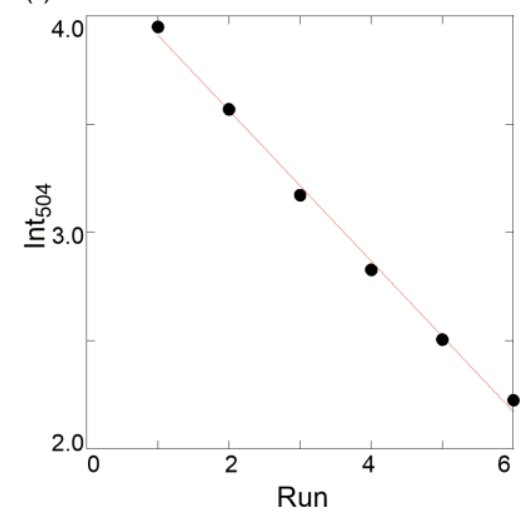

(u)
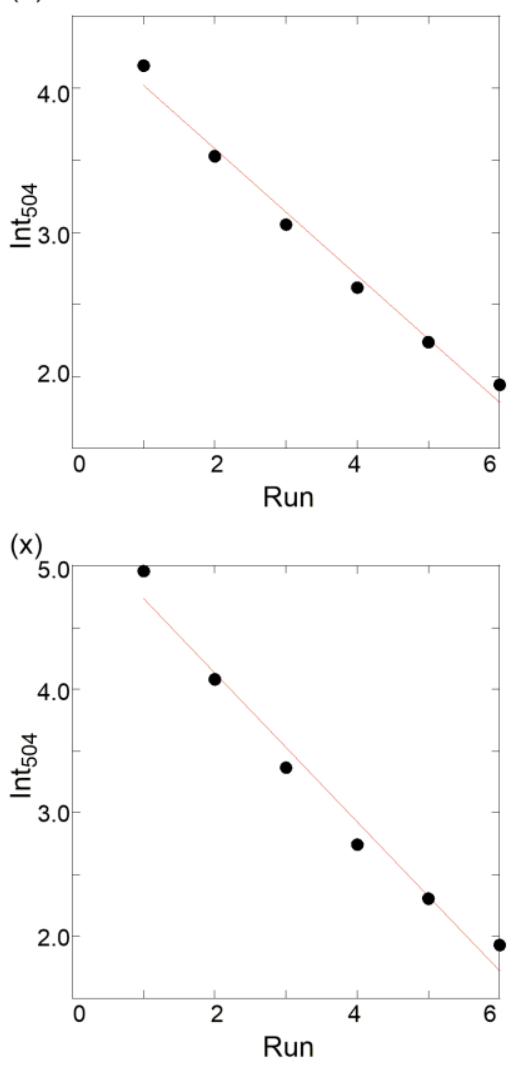

Figure S16. Fluorescence spectra $\left(\lambda_{\mathrm{ex}} 320 \mathrm{~nm}\right)$ of $\mathrm{DMSO}_{2} \mathrm{O}(1: 9, \mathrm{v} / \mathrm{v})$ solutions of TPE $\mathrm{H}_{\mathrm{low}}-\mathrm{PE}$ $(9.8 \mu \mathrm{M}$ ) at (a) $0.1 \mathrm{MPa}$, (d) $40 \mathrm{MPa}$, (g) $80 \mathrm{MPa}$, (j) $120 \mathrm{MPa},(\mathrm{m}) 160 \mathrm{MPa}$, (p) $200 \mathrm{MPa}$, (s) 240 $\mathrm{MPa}$, and (v) $280 \mathrm{MPa}$ at room temperature in a high-pressure cell upon irradiation for the 1st (black), 2nd (red), 3rd (pink), 4th (orange), 5th (green), and 6th (blue) runs. Plots of fluorescence intensity changes at $380 \mathrm{~nm}(\mathrm{~b}, \mathrm{e}, \mathrm{h}, \mathrm{k}, \mathrm{n}, \mathrm{q}, \mathrm{t}, \mathrm{w})$ and $504 \mathrm{~nm}(\mathrm{c}, \mathrm{f}, \mathrm{i}, \mathrm{l}, \mathrm{o}, \mathrm{r}, \mathrm{u}, \mathrm{x})$ upon each irradiation. 
(a)

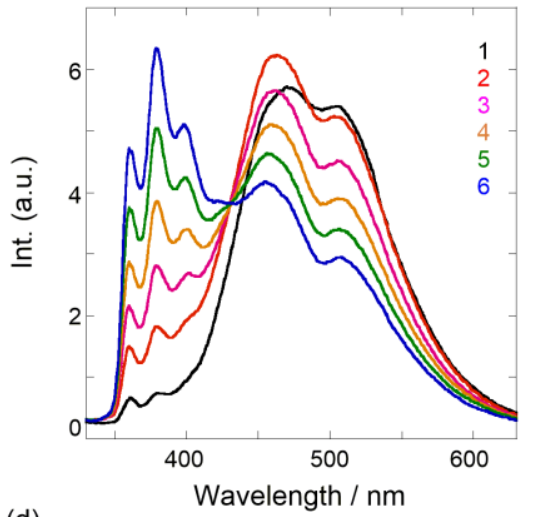

(d)

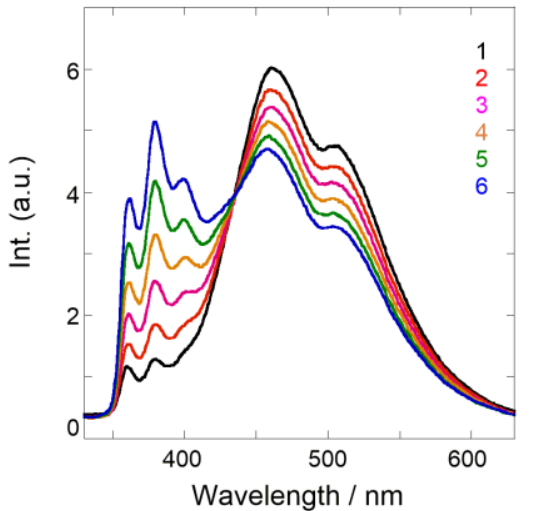

(g)

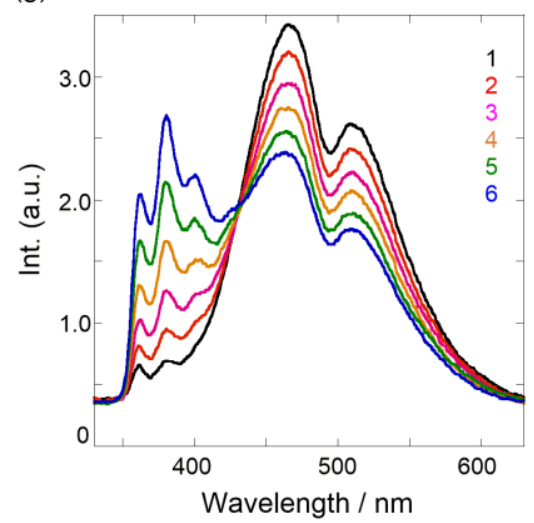

(j)

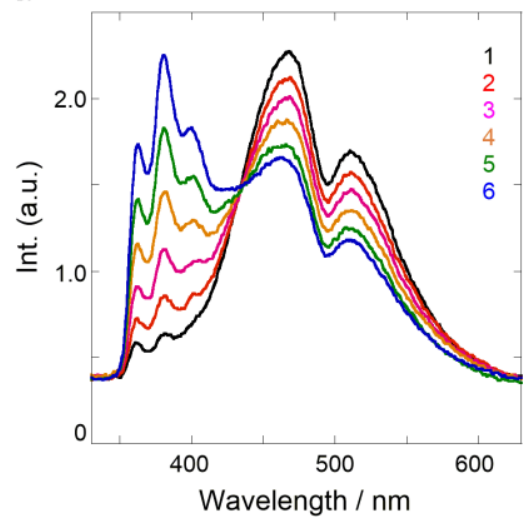

(b)

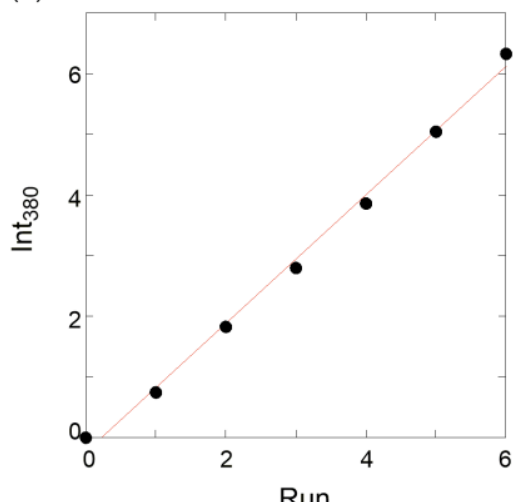

(e)

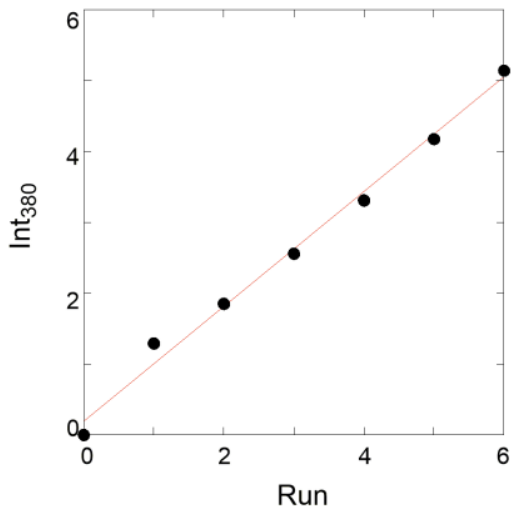

(h)

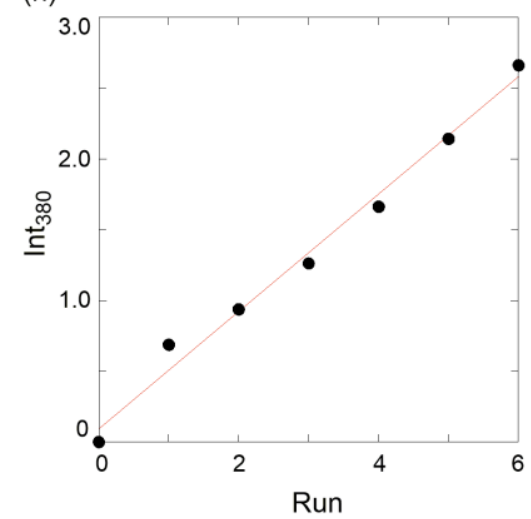

(k)

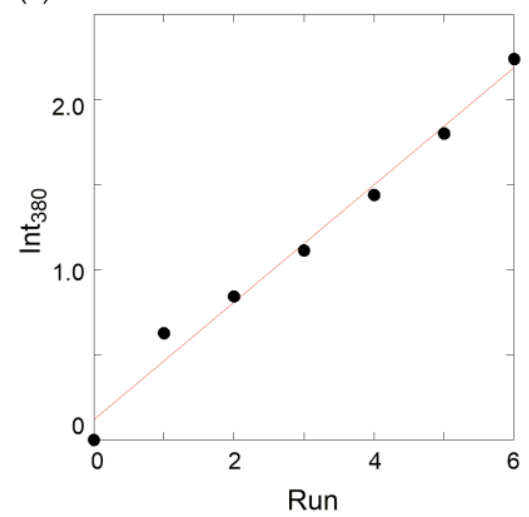

(c)
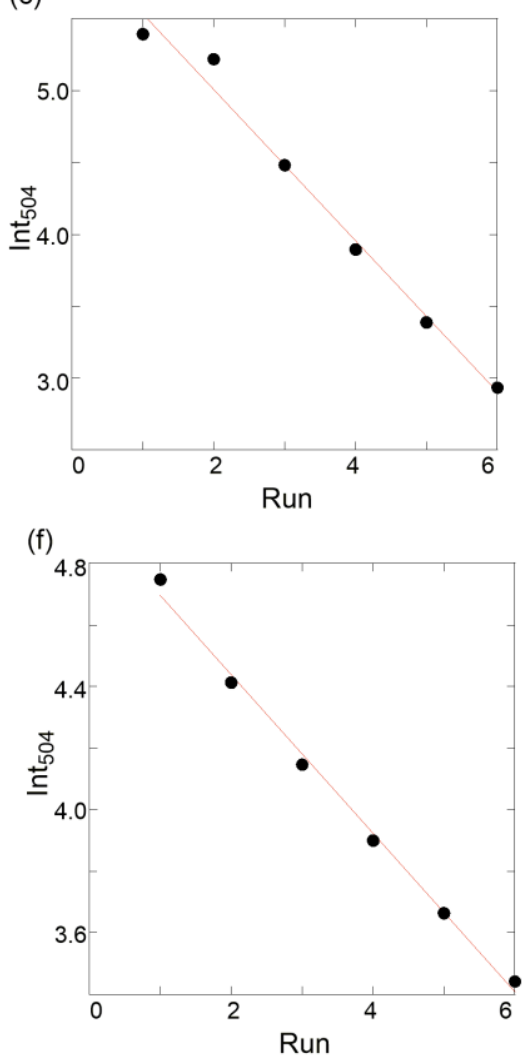

(i)

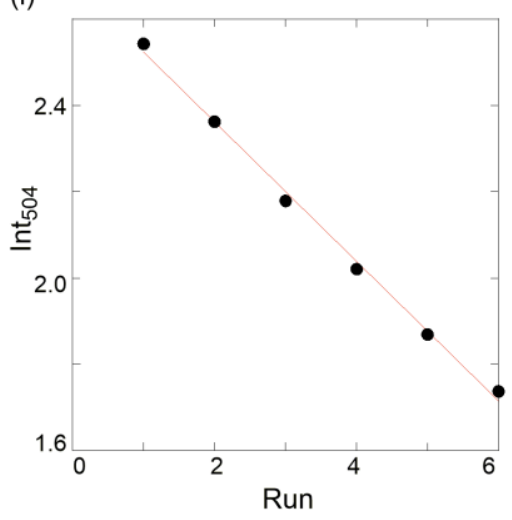

(I)

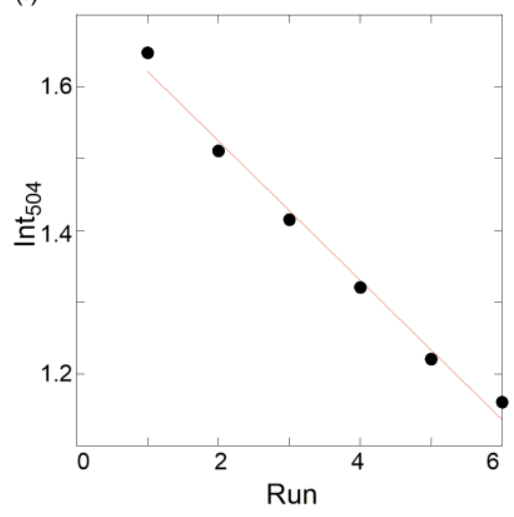


(m)

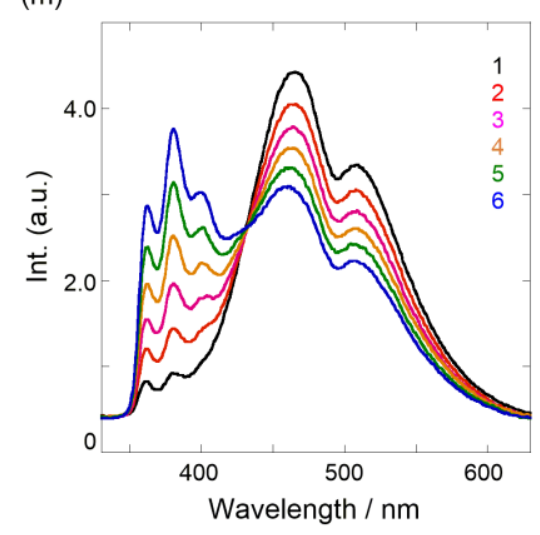

(p)

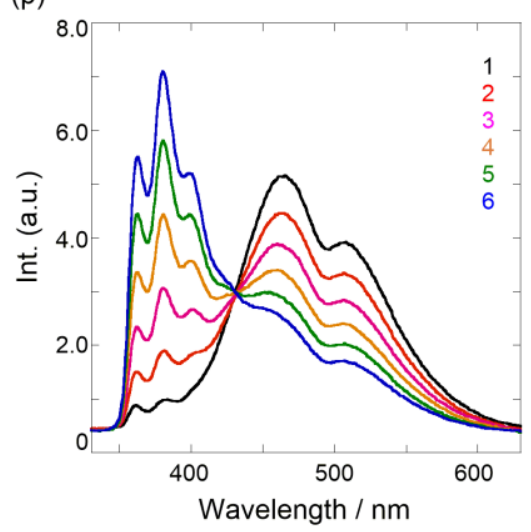

(s)

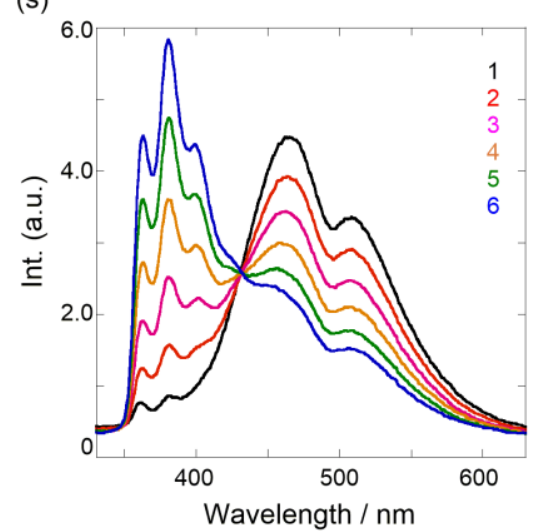

(v)

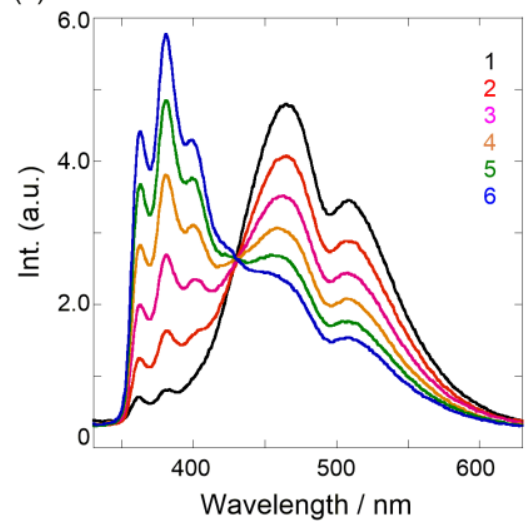

(n)

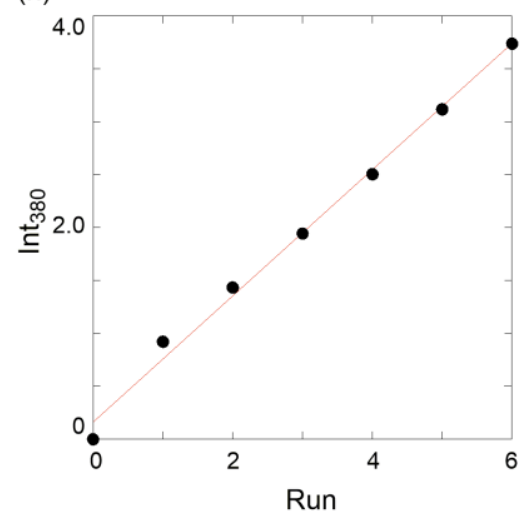

(q)

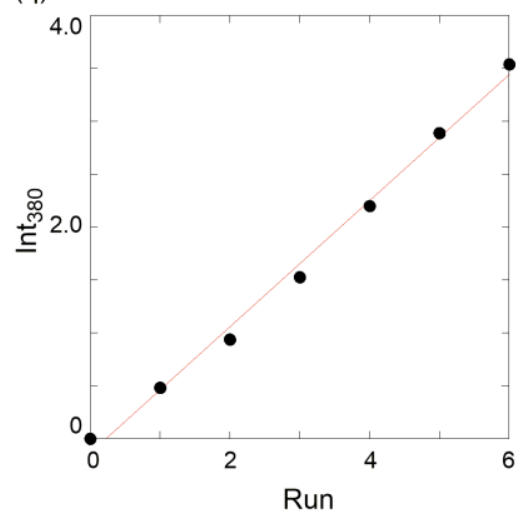

(t)

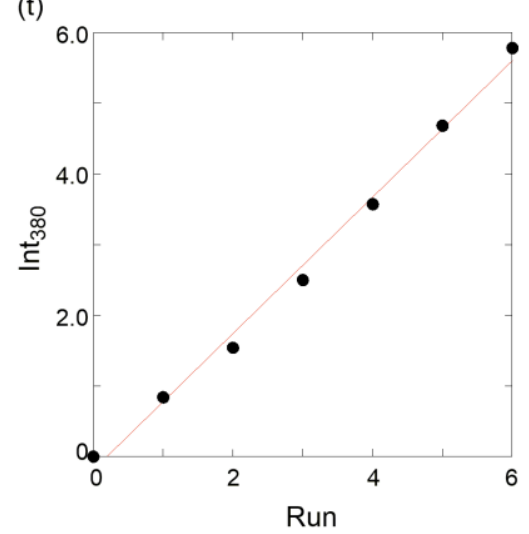

(w)

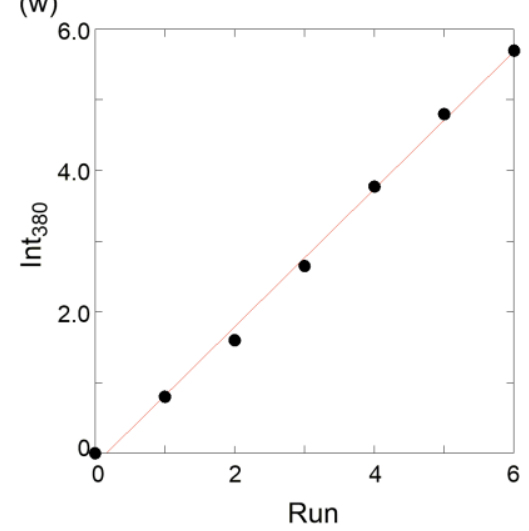

(o)

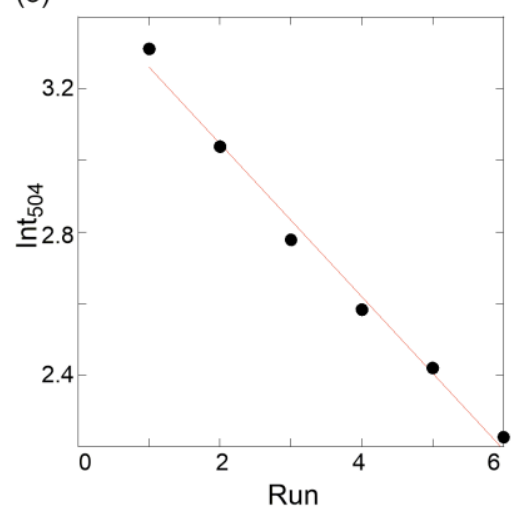

(r)

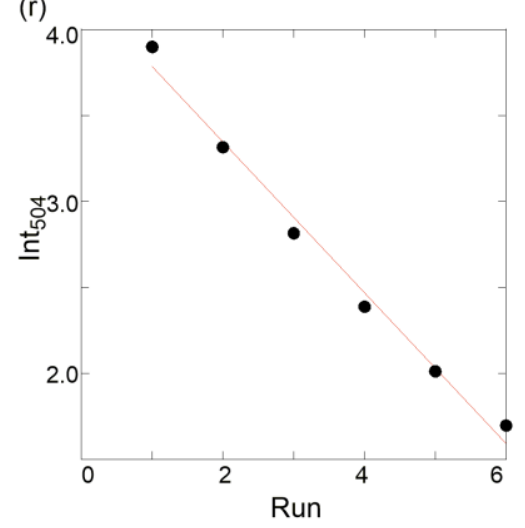

(u)

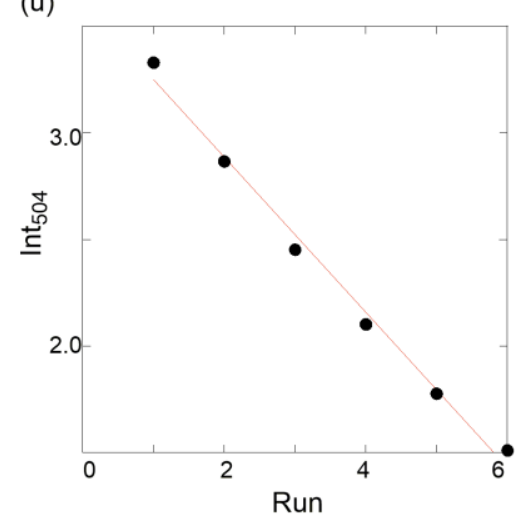

(x)

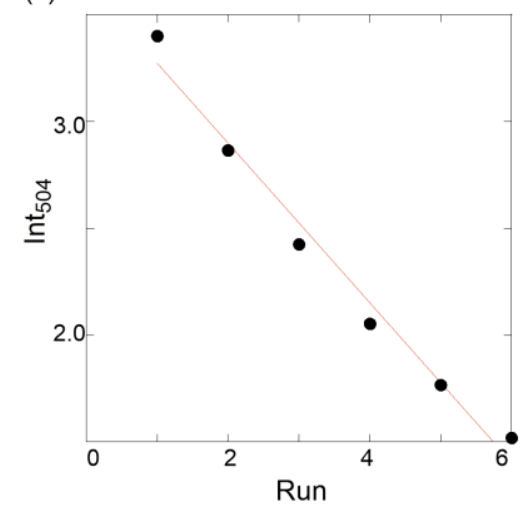

Figure S17. Fluorescence spectra $\left(\lambda_{\text {ex }} 320 \mathrm{~nm}\right)$ of DMSO- $\mathrm{H}_{2} \mathrm{O}(1: 9, \mathrm{v} / \mathrm{v})$ solutions of TPE $\mathbf{m i d}_{\text {mid }} \mathbf{P E}$ $(9.8 \mu \mathrm{M}$ ) at (a) $0.1 \mathrm{MPa}$, (d) $40 \mathrm{MPa}$, (g) $80 \mathrm{MPa}$, (j) $120 \mathrm{MPa},(\mathrm{m}) 160 \mathrm{MPa}$, (p) $200 \mathrm{MPa}$, (s) 240 $\mathrm{MPa}$, and (v) $280 \mathrm{MPa}$ at room temperature in a high-pressure cell upon irradiation for the 1st (black), 2nd (red), 3rd (pink), 4th (orange), 5th (green), and 6th (blue) runs. Plots of fluorescence intensity changes at $380 \mathrm{~nm}(\mathrm{~b}, \mathrm{e}, \mathrm{h}, \mathrm{k}, \mathrm{n}, \mathrm{q}, \mathrm{t}, \mathrm{w})$ and $504 \mathrm{~nm}(\mathrm{c}, \mathrm{f}, \mathrm{i}, \mathrm{l}, \mathrm{o}, \mathrm{r}, \mathrm{u}, \mathrm{x})$ upon each irradiation. 
(a)

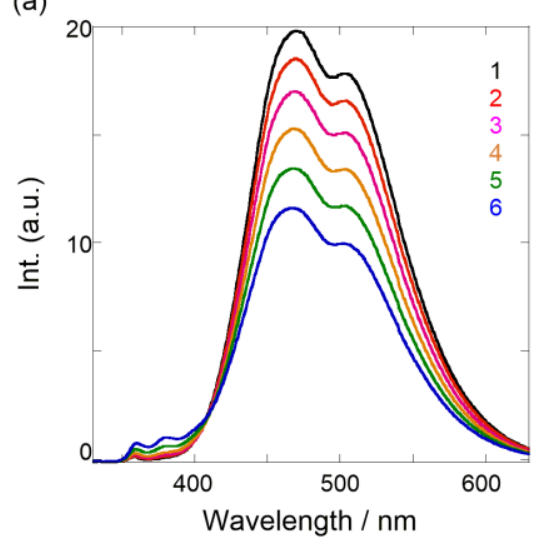

(d)

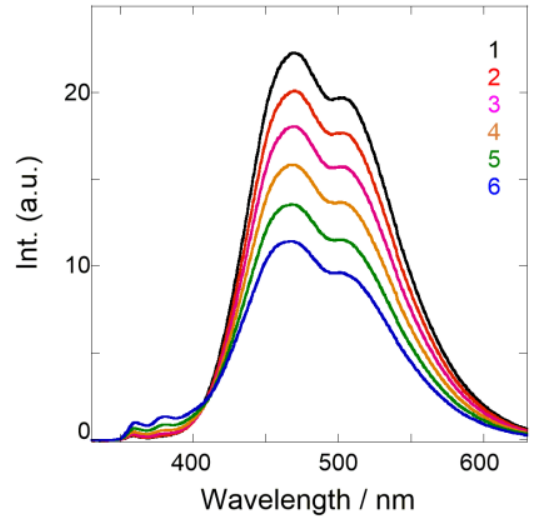

(g)

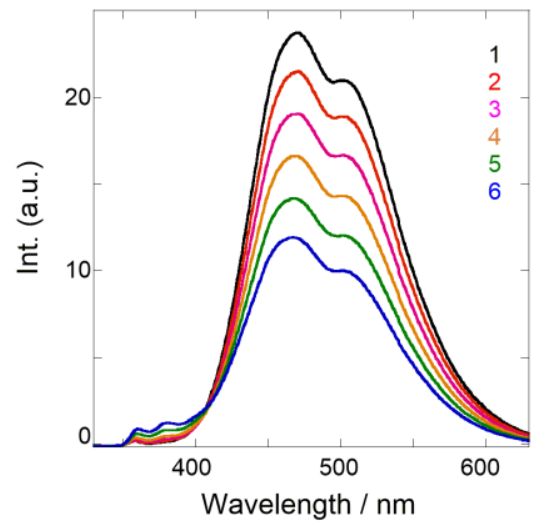

(j)

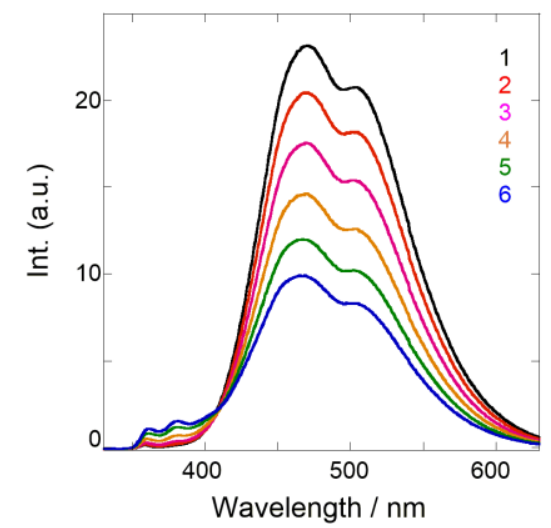

(b)

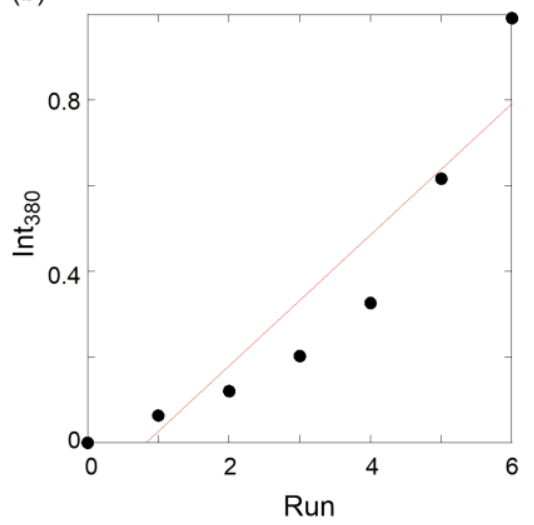

(e)

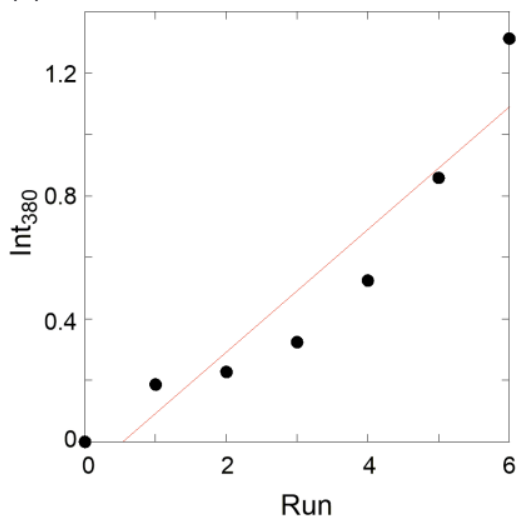

(h)

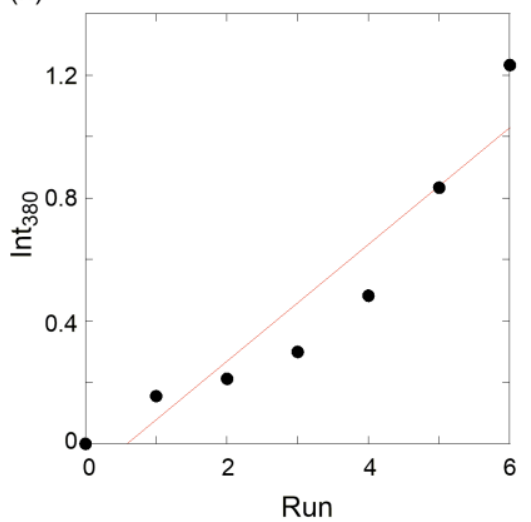

(k)

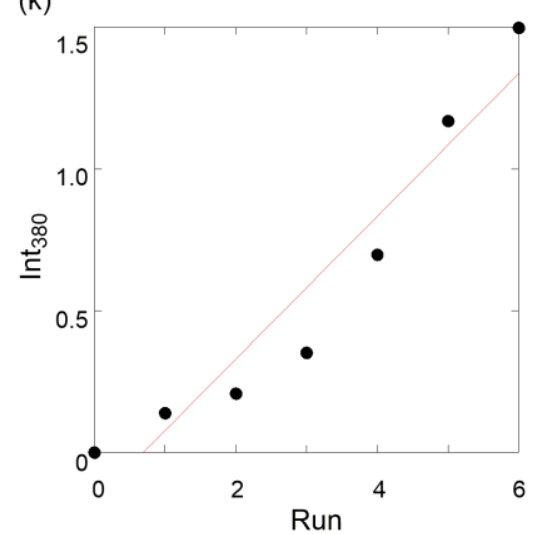

(c)
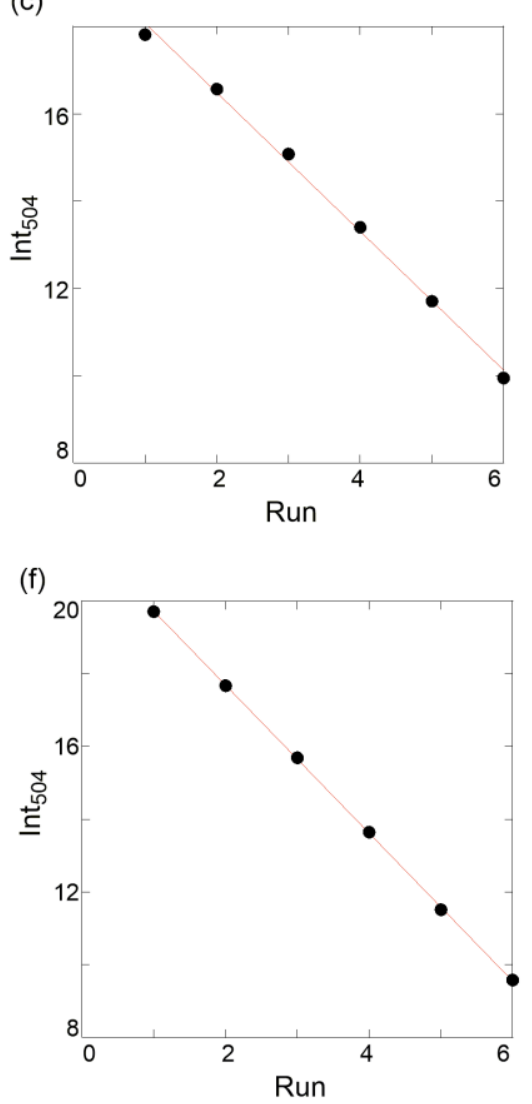

(i)

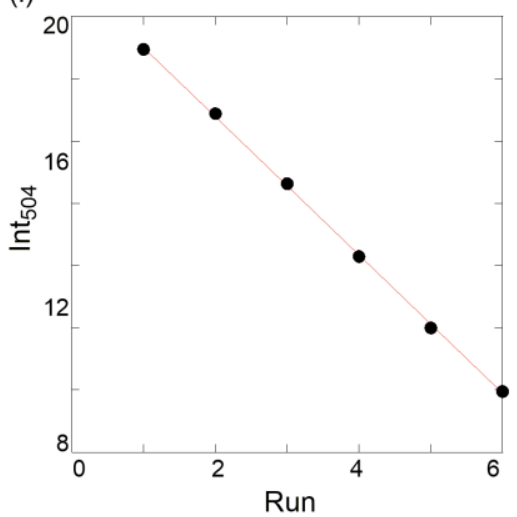

(I)

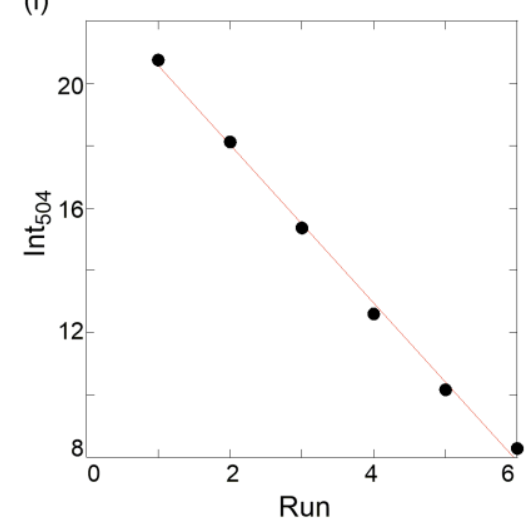


(m)

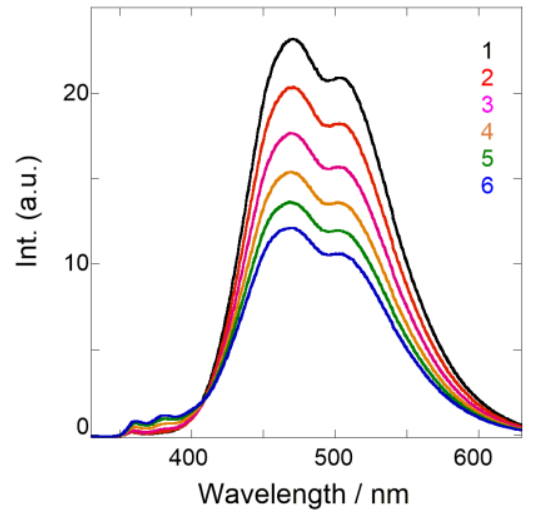

(p)

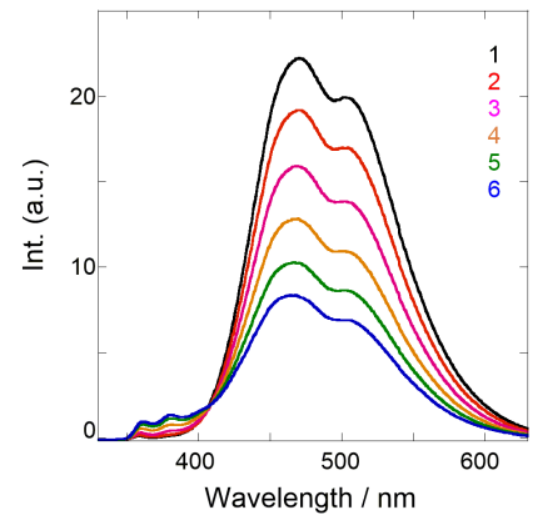

(s)

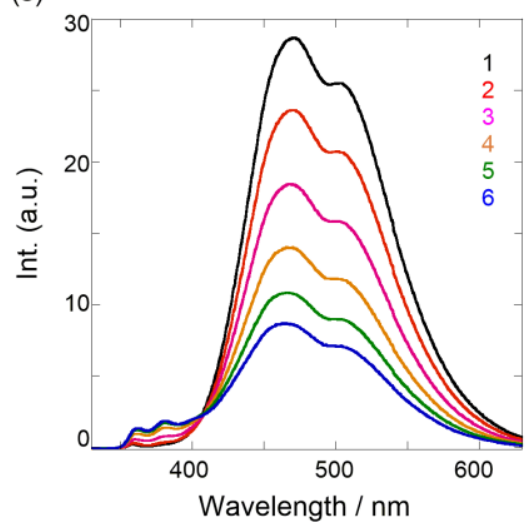

(

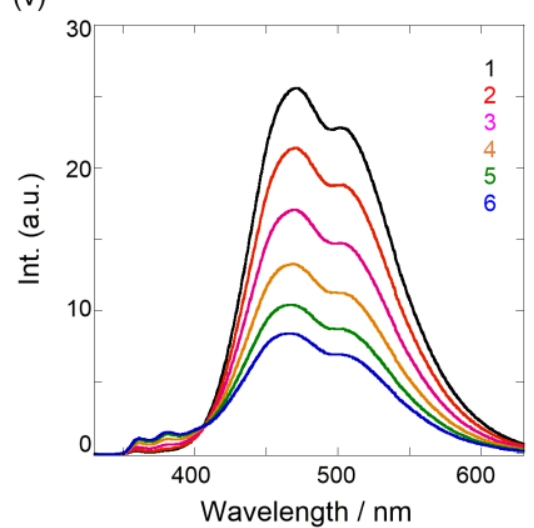

(n)

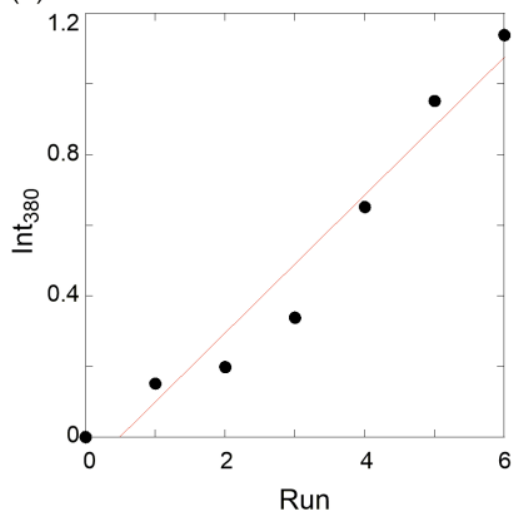

(q)

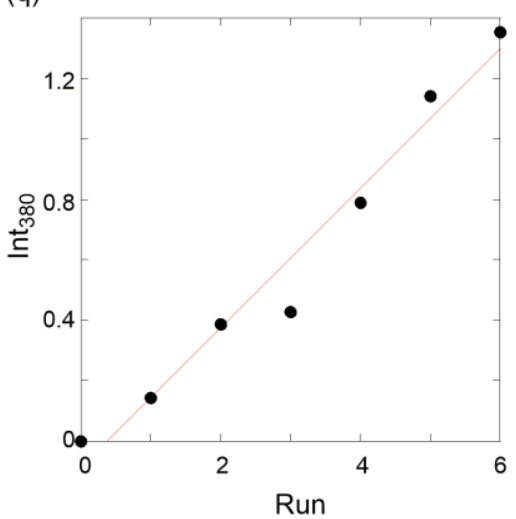

(t)

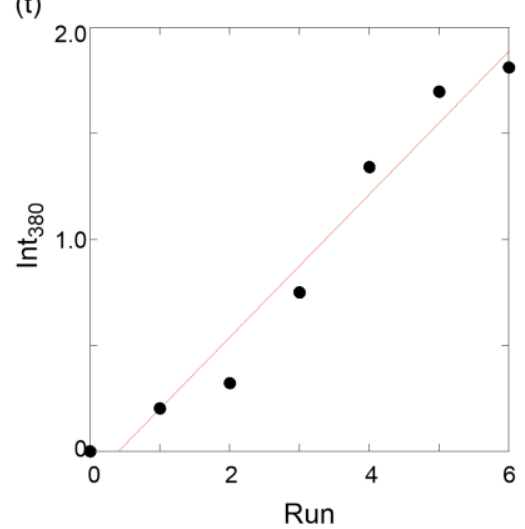

(w)

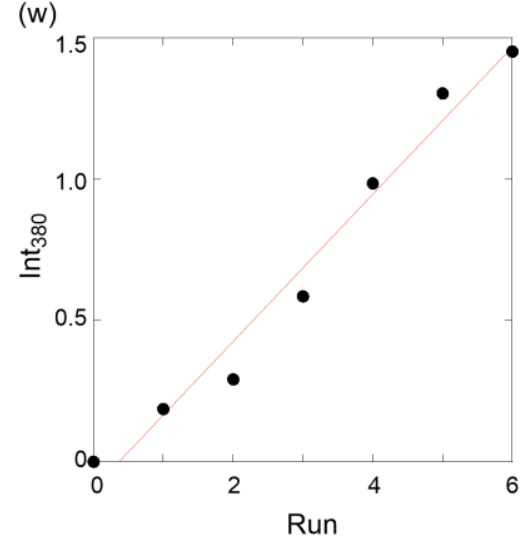

(o)

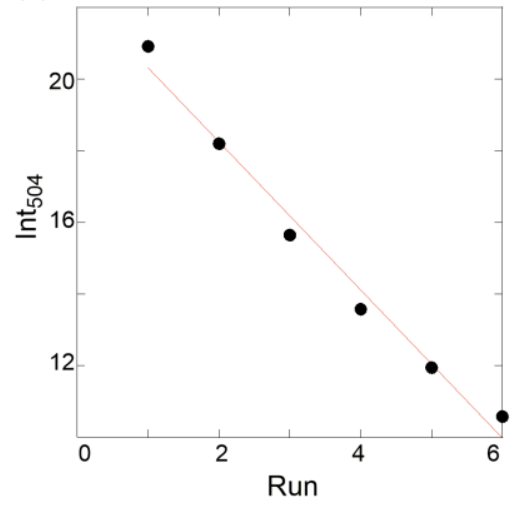

(r)

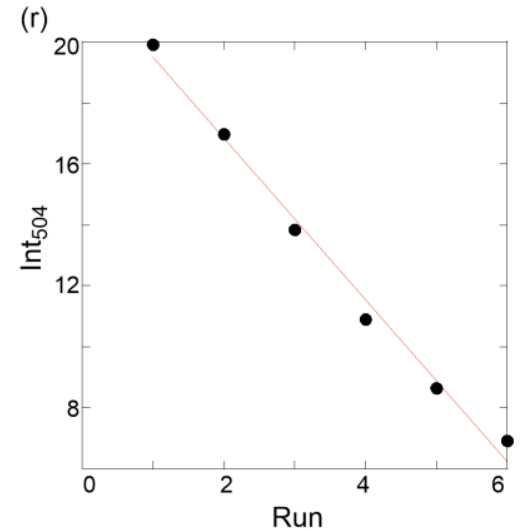

(u)
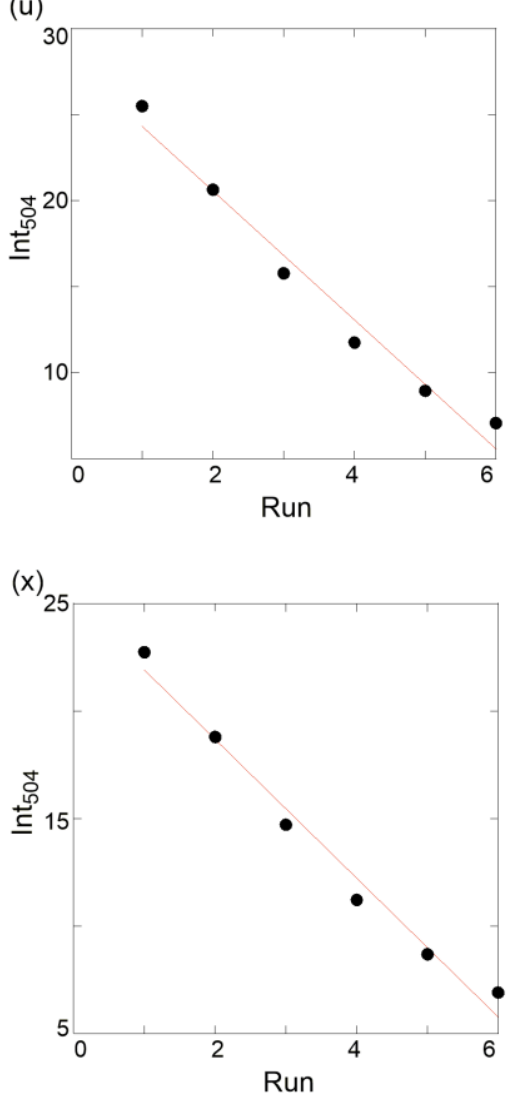

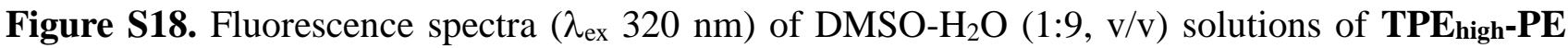
$(9.8 \mu \mathrm{M}$ ) at (a) $0.1 \mathrm{MPa}$, (d) $40 \mathrm{MPa},(\mathrm{g}) 80 \mathrm{MPa},(\mathrm{j}) 120 \mathrm{MPa},(\mathrm{m}) 160 \mathrm{MPa}$, (p) $200 \mathrm{MPa}$, (s) 240 $\mathrm{MPa}$, and (v) $280 \mathrm{MPa}$ at room temperature in a high-pressure cell upon irradiation for the 1st (black), 2nd (red), 3rd (pink), 4th (orange), 5th (green), and 6th (blue) runs. Plots of fluorescence intensity changes at $380 \mathrm{~nm}(\mathrm{~b}, \mathrm{e}, \mathrm{h}, \mathrm{k}, \mathrm{n}, \mathrm{q}, \mathrm{t}, \mathrm{w})$ and $504 \mathrm{~nm}(\mathrm{c}, \mathrm{f}, \mathrm{i}, \mathrm{l}, \mathrm{o}, \mathrm{r}, \mathrm{u}, \mathrm{x})$ upon each irradiation. 
Pressure-Induced $\gamma$ Values

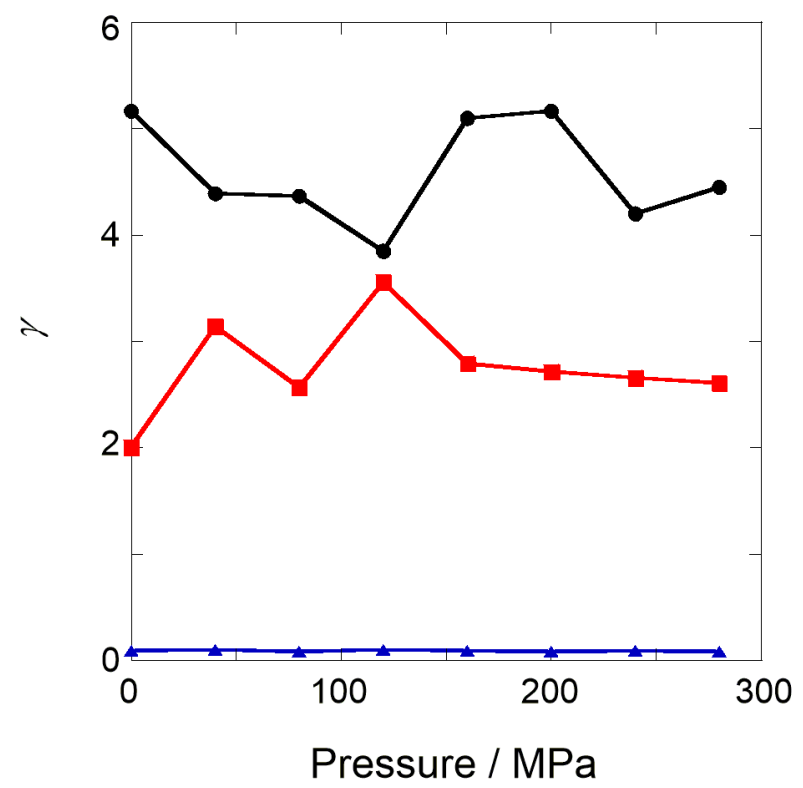

Figure S19. Plots of $\gamma$ values as a function of pressure for TPE $\mathbf{E}_{\text {low }} \mathbf{P E}$ (black circle), TPEmid-PE

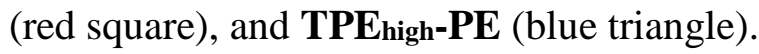




\section{References}

1. Shi, H.; Kwok, R. T. K.; Liu, J.; Xing, B.; Tang, B. Z.; Liu, B. Real-Time Monitoring of Cell Apoptosis and Drug Screening Using Fluorescent Light-Up Probe with Aggregation-Induced Emission Characteristics. J. Am. Chem. Soc. 2012, 134, 17972-17981.

2. Wu, X.; Han, J.; Wang, L. Palladium Catalyzed C-I and Vicinal C-H Dual Activation of Diaryliodonium Salts for Diarylations: Synthesis of Triphenylenes. J. Org. Chem. 2018, 83, 49-56.

3. Huang, Z.; Zhang, X.; Zhang, X.; Wang, S.; Yang, B.; Wang, K.; Yuan, J.; Tao, L.; Wei, Y. Synthesis of Amphiphilic Fluorescent PEGylated AIE Nanoparticles via RAFT Polymerization and Their Cell Imaging Applications. RSC Adv. 2015, 5, 89472-89477. 